\title{
The impact of sleep loss on sustained and transient attention: An EEG study
}

\author{
Lucienne Shenfield $^{\text {Corresp., } 1}$, Vanessa Beanland ${ }^{2}$, Ashleigh Filtness ${ }^{3}$, Deborah Apthorp ${ }^{\text {Corresp. 4, } 5}$ \\ 1 Research School of Psychology, Australian National University, Canberra, ACT, Australia \\ 2 Department of Psychology, University of Otago, Dunedin, New Zealand \\ 3 School of Design and Creative Arts, Loughborough University, Loughborough, Leicestershire, United Kingdom \\ 4 School of Psychology, University of New England, Armidale, NSW, Australia \\ 5 Research School of Computer Science, Australian National University, Canberra, ACT, Australia \\ Corresponding Authors: Lucienne Shenfield, Deborah Apthorp \\ Email address: lucienne.shenfield@gmail.com, dapthorp@une.edu.au
}

Sleep is one of our most important physiological functions that maintains physical and mental health. Two studies examined whether discrete areas of attention are equally affected by sleep loss. This was achieved using a repeated-measures within-subjects design, with two contrasting conditions: normal sleep and partial sleep restriction of fivehours. Study 1 compared performance on a sustained attention task (Psychomotor Vigilance task; PVT) with performance on a transient attention task (Attentional Blink; $A B$ ). PVT performance, but not performance on the AB task, was impaired after sleep restriction. Study 2 sought to determine the neural underpinnings of the phenomenon, using electroencephalogram (EEG) frequency analysis, which measured activity during the brief eyes-closed resting state before the tasks. AB performance was unaffected by sleep restriction, despite clearly observable changes in brain activity. EEG results showed a significant reduction in resting state alpha oscillations that was most prominent centrally in the right hemisphere. Changes in individual alpha and delta power were also found to be related to changes in subjective sleepiness and PVT performance. Results likely reflect different levels of impairment in specific forms of attention following sleep loss. 


\section{The Impact of Sleep Loss on Sustained and Transient Attention: An EEG Study}

2

3 Lucienne Shenfield ${ }^{1}$, Vanessa Beanland ${ }^{2}$, Ashleigh Filtness ${ }^{5}$, Deborah Apthorp ${ }^{3,4}$

4

$5{ }^{1}$ Research School of Psychology, Australian National University, Canberra, ACT 2601,

6 Australia

72 Department of Psychology, University of Otago, Dunedin 4150, New Zealand

$8{ }^{3}$ School of Psychology, University of New England, Armidale, NSW 2351, Australia

$9{ }^{4}$ Research School of Computer Science, Australian National University, Canberra, ACT 2601,

10 Australia

$11{ }^{5}$ School of Design and Creative Arts, Loughborough University, Loughborough, Leicestershire,

12 LE11 3TU, UK

13

14 Corresponding Authors:

15 Lucienne Shenfield

16 88/3 London Circuit, Canberra, ACT 2602 Australia

17 Email address: lucienne.shenfield@gmail.com

18 Deborah Apthorp

19 School of Psychology, University of New England, Armidale, NSW 2351, Australia

20 Email address: dapthorp@une.edu.au 


\section{Abstract}

22 Sleep is one of our most important physiological functions that maintains physical and mental

23 health. Two studies examined whether discrete areas of attention are equally affected by sleep

24 loss. This was achieved using a repeated-measures within-subjects design, with two contrasting

25 conditions: normal sleep and partial sleep restriction of five-hours. Study 1 compared

26 performance on a sustained attention task (Psychomotor Vigilance task; PVT) with performance

27 on a transient attention task (Attentional Blink; AB). PVT performance, but not performance on

28 the AB task, was impaired after sleep restriction. Study 2 sought to determine the neural

29 underpinnings of the phenomenon, using electroencephalogram (EEG) frequency analysis, which

30 measured activity during the brief eyes-closed resting state before the tasks. AB performance

31 was unaffected by sleep restriction, despite clearly observable changes in brain activity. EEG

32 results showed a significant reduction in resting state alpha oscillations that was most prominent

33 centrally in the right hemisphere. Changes in individual alpha and delta power were also found to

34 be related to changes in subjective sleepiness and PVT performance. Results likely reflect

35 different levels of impairment in specific forms of attention following sleep loss. 


\section{Introduction}

\subsection{Sleep and Attention}

Healthy sleep habits are imperative to maintaining physical and psychological health and wellbeing (American Academy of Sleep Medicine, 2014; Hirshkowitz et al., 2015), while sleep loss is associated with physical and mental health problems (American Psychiatric Association, 2013). Costs associated with sleep loss in Australia were estimated at \$36.4 billion in 2010 (Deloitte Access Economics, 2011). Despite this, recent evidence suggests that the number of hours people habitually sleep per night has continued to decline (Knutson, Van Cauter, Rathouz, DeLeire, \& Lauderdale, 2010; Matricciani, Olds, \& Williams, 2011).

As discussed by Owens (2009), considerable empirical evidence indicates that the central nervous system centres which regulate sleep overlap with those that regulate attention/arousal. This suggests that a disruption in one system is likely to be reflected by a disruption in the other system. Research suggests that sleep loss tends to impair attention, but 'attention' encapsulates a wide range of different paradigms and phenomena. As noted by Whitney and Hinson (2010) and Raz (2004), many studies have broadly claimed that sleep deprivation negatively impacts all areas of attention. However, few empirical studies have sought to evaluate each separate interrelated process within the individual cognitive tasks. Even simple cognitive tasks typically involve multiple underlying cognitive processes, and some task components may be more susceptible to the effects of sleep deprivation than others.

\subsection{Vigilance and the Psychomotor Vigilance Task (PVT)}

Vigilance is defined as the ability to sustain attention over an extended period of time (Oken, Salinsky, \& Elsas, 2006). Sustained, focused, endogenous, and vigilant attention can be 
58 viewed as synonymous terms (Carrasco, 2011). Vigilant attention has often been examined in the

59 context of sleep loss and it appears to be highly susceptible to its effects (Lim \& Dinges, 2008).

60 Vigilance tasks include the Continuous Stimulus Detection or Discrimination tasks

61 (Langner \& Eickhoff, 2013), Continuous Performance Test (Riccio, Reynolds, Lowe, \& Moore,

62 2002), Go-No-Go test (Ayalon, Ancoli-Israel, Aka, McKenna, \& Drummond, 2009), and

63 Psychomotor Vigilance Task (PVT; Dinges \& Powell, 1985). The PVT involves a 10-minute

64 trial in which participants are instructed to respond to a stimulus (e.g. a millisecond counter) by

65 pressing a button as quickly as possible when it appears at random intervals, usually 2-10

66 seconds. This randomised inter-trial-interval (ITI) is integral in differentiating the PVT from a

67 standard reaction time task, as it eliminates the opportunity for anticipation, forcing participants

68 to be constantly vigilant (Basner \& Dinges, 2011). The PVT (Dinges \& Powell, 1985) has an

69 extensive history of use in sleep-related research (Lim \& Dinges, 2010), reliably finding that

70 sleep loss results in poorer performance.

\section{1.1. Transient Attention and the Attentional Blink (AB)}

72 The concept of sustained attention is relatively well understood, but less is known about

73 transient attention (Liu, Pestilli, \& Carrasco, 2005), which involves the ability to attend to brief,

74 fleeting tasks or stimuli. Transient attention tasks are thought to facilitate greater attentional

75 intensity than sustained attention tasks (Carrasco, 2011). Transient attention rises and decays

76 quickly and typically has a duration of less than 10 seconds (Suri, Sheppes, Leslie, \& Gross,

77 2014), with a peak intensity of 100-120 ms post initiation (Carrasco, 2011). Arguably, the most

78 widely used test of transient attention is the attentional blink ( $\mathrm{AB}$ ) paradigm (Dux \& Marois, 79 2009). 

distractors, but has a reduced ability to perceive a second target (T2) when it is presented within $800 \mathrm{~ms}$ of T1 (see Figure 1). The phenomenon was first documented by Broadbent and Broadbent (1987) and was named 'attentional blink' in 1992 by Raymond and colleagues. This term does not refer to a physical blink, but rather, a momentary lapse in attentional ability (Shapiro, Raymond, \& Arnell, 1997). The event is typically measured using a Rapid Serial Visual Presentation (RSVP) task developed by Potter and Levy (1969). During the task, distractor and target stimuli are displayed in quick succession, usually about $100 \mathrm{~ms}$ apart, to test information processing limits. For a thorough review of research and theories pertaining to $\mathrm{AB}$, see Dux and Marois (2009). While PVT performance has been extensively researched in relation to sleep, less is known about the relationship between AB performance and sleep loss.

\section{[INSERT FIGURE 1 ABOUT HERE]}

\subsection{Electroencephalogram (EEG)}

$\mathrm{AB}$ research has frequently used Electroencephalography (EEG). EEG is a reliable and

94 valid way of measuring the brain activity associated with different levels of consciousness

95 (Antonenko, Paas, Grabner, \& van Gog, 2010), and has greatly advanced our understanding of

96 the neural processes associated with sleep and wakefulness (Strijkstra, Beersma, Drayer,

97 Halbesma, \& Daan, 2003). EEG is sensitive to activity of cortico-thalamic networks that underlie

98 the dimensions of sleep and wakefulness (Steriade, 1999). For this reason, EEG has an extensive

99 history of use in sleep and attention research (Berka et al., 2007; Hoedlmoser et al., 2011;

100 Strijkstra et al., 2003). However, the majority of previous research using EEG to investigate the

101 effects of sleep loss has focused on total sleep deprivation, rather than sleep restriction (Borbély,

102 Baumann, Brandeis, Strauch, \& Lehmann, 1981; Kaida et al., 2006). Sleep deprivation is defined

103 as a night in which no sleep occurs, while sleep loss/restriction is defined as a night in which a 
104 person sleeps less than is typical (Reynolds \& Banks, 2010). In general, the effects of sleep

105 deprivation are thought to be more severe than the effects of sleep restriction (Reynolds \&

106 Banks, 2010).

107 The measurement of neural activity using EEG enables the detection of synchronous

108 activity in neurons which fire rhythmically in the cortex to produce distinct EEG waveforms

109 (Tong \& Thakor, 2009). Neural oscillations vary in their amplitude and frequency, and they are

110 generally separated into five bandwidths, referred to as delta $(0-4 \mathrm{~Hz})$, theta $(4-8 \mathrm{~Hz})$, alpha (8-

$11112 \mathrm{~Hz})$, beta $(12-40 \mathrm{~Hz})$, and gamma $(40-100 \mathrm{~Hz})$. Sleep has been linked to various wavelengths

112 including alpha, theta, and delta (Benca et al., 1999; Boonstra, Daffertshofer, \& Beek, 2005;

113 Borbély et al., 1981; Cajochen, Foy, \& Dijk, 1999; Harmony et al., 1996; Kaida et al., 2006;

114 Klimesch, 1999; Strijkstra et al., 2003). Additional findings regarding neural activity have linked

115 alpha oscillations to visual attention (Capotosto, Babiloni, Romani, \& Corbetta, 2009; Ergenoglu

116 et al., 2004; Mathewson et al., 2011), temporal attention (Hanslmayr, Gross, Klimesch, \&

117 Shapiro, 2011), and the AB (Händel, Haarmeier, \& Jensen, 2011; Maclean \& Arnell, 2011;

118 MacLean, Arnell, \& Cote, 2012; Zauner et al., 2012). Subjective sleepiness and PVT

119 performance have been linked to delta and theta oscillations (Hoedlmoser et al., 2011).

$120 \quad 1 . \quad$ Study 1

121 Study 1 investigated the impact of sleep loss on sustained and transient attention, using the

122 PVT and AB paradigms. Prior research has shown that the two tasks are equivalent in terms of

123 task difficulty/engagement (Shenfield, Beanland, \& Apthorp, 2020). Consistent with the

124 abovementioned literature, it was hypothesised that performance would be impaired on (i) the

125 PVT and (ii) the AB after sleep restriction. 


\section{2. Study 1 Method}

\section{2.1. Participants}

128 Twenty-four adults (12 female; $M_{\text {age }}=26.0$ years, $\left.S D=3.9\right)$ were recruited from among

129 the staff and students at Queensland University of Technology (QUT). Study inclusion criteria

130 were that participants were aged 18-30 years and regularly slept 7-8 hours/night. Study

131 exclusion criteria were current smokers, sleep/medical/mental health problems other than minor

132 illnesses, high caffeine users ( $>5$ caffeinated drinks/day), regular daytime nappers, and shift-

133 workers. All participants received AUD\$60 on completion of the study. The study was

134 conducted with full ethics approval from the QUT Human Research Ethics Committee (HREC;

135 Protocol \#1300000793).

\section{2.2. Design and Procedure}

The study used a repeated-measures design. Participants completed two testing sessions:

138 (i) after a normal night's sleep (NS), and (ii) after sleep restriction (SR) to 5 hours', with session

139 order counterbalanced between participants. The sessions were scheduled approximately 1 week

140 apart. To ensure the standardisation of the sleep restriction, participants reduced their sleep to 5

141 hours by delaying bedtime by 3 hours, so that all experienced early night sleep restriction, as

142 opposed to late night sleep restriction, which can affect attention differently (Zerouali, Jemel, \&

143 Godbout, 2010). To ensure compliance, participants kept a sleep diary for 3 nights prior to each

144 testing session, estimating their sleep onset, morning wakening, and rising times. They also

145 phoned an answering service prior to going to bed and after waking each morning, and the times

146 were used to verify the diary entries (Ibáñez, Silva, \& Cauli, 2018) and confirm that the

147 participants typically slept 7-8 hours/night. 
148 Participants were instructed not to consume alcohol from 18:00h the night prior to the

149 study and not to consume caffeine on the day of the study. They were instructed to have

150 breakfast as usual and a light lunch. They were asked to arrive to the study at 14:00h, as this has

151 been identified as an optimal time to measure the effects of sleep loss (Lenné, Triggs, \&

152 Redman, 1997). At this time, they provided informed written consent, completed the

153 demographics questionnaire, then rated their subjective sleepiness. They were required to

154 undertake two computer-based tasks: (i) the AB task; and (ii) the PVT. After a brief explanation

155 of the tasks, they completed 10 practice trials of the AB task and 5 minutes' practice of the PVT.

156 After both practice sessions, the AB task was completed and then the PVT, with a short break in

157 between the tasks.

\section{2.3. Apparatus}

159 Both tasks were presented on the same computer using a 19-inch $100 \mathrm{~Hz}$ CRT monitor.

\section{2.4. Stimuli}

161 2.4.1. Psychomotor Vigilance Task (PVT)

162 Stimuli were presented over a 10-minute period, and the length of the interval between

163 the stimuli ranged randomly from 1 to 9 seconds. Participants were seated at the computer with

164 their dominant hand on a computer mouse. They were instructed to respond immediately when a

165 digital millisecond counter appeared on the screen.

\section{2.4.2. Attentional Blink (AB)}

167 A custom AB program was written in Presentation (Neurobehavioural Systems, Inc). Each

168 trial was comprised of 10 items: 8 distractors and 2 targets. Items were presented using RSVP in

169 Times New Roman 50-point font. Distractors were all uppercase letters of the alphabet except

170 those that might be confused with numbers (I, O, Q and S). Targets were the digits 2 to 9 
171 inclusive. Two targets were presented in each trial. T2 appeared either immediately after T1 (lag

172 1) or after 1-7 distractors (lags 2-8). After each trial, participants used the number pad on the

173 keyboard to indicate the two targets that had been presented. There were 160 experimental trials,

17420 for each lag. The task took approximately 12 minutes to complete.

175 2.4.3. Subjective Sleepiness

176 All participants provided ratings of subjective sleepiness at the start and the end of each

177 testing session using the 9 item Karolinska Sleepiness Scale (KSS; Åkerstedt \& Gillberg, 1990;

178 Kaida et al., 2006).

\section{2.5. Statistical Analysis}

180 All data were inspected for normality and homoscedasticity. Subjective sleepiness (KSS)

181 and PVT were compared between the SR and NS conditions using paired $t$-tests. Dependent

182 measures derived from the PVT were mean reciprocal response time (RRT; 1/reaction time),

183 standard deviation of RRT, slowest 10\% RRT, number of lapses (RT $>500 \mathrm{~ms}$ ), and number of

184 false starts (RT $\leq 100 \mathrm{~ms})$. False start reaction times were not included in the RRT calculations.

185 Data for lapses and false starts were square rooted to normalise the distributions.

186 The $\mathrm{AB}$ dependent measures was the percentage of $\mathrm{T} 2$ items correctly identified in cases

187 where $\mathrm{T} 1$ was correctly identified (T2|T1), which was analysed using a two-way $2 \times 8$ repeated

188 measures analysis of variance (ANOVA) testing condition (2) and lag (8). Greenhouse-Geisser

189 adjustments were made in the case that the assumption of sphericity was not met. All analyses

190 were evaluated using an alpha level of .05. 


\section{$191 \quad 3 . \quad$ Study 1 Results}

\section{3.1. Sleep Characteristics Subjective Sleepiness}

193 The results presented in Table 1 show that the SR manipulation was effective in

194 significantly decreasing the amount of actual sleep and increasing the level of subjective

195 sleepiness reported by participants.

196 Table 1. Duration of sleep and subjective sleepiness by testing session.

197 3.2. PVT

198 PVT results are presented in Table 2. SR significantly slowed participants' reaction time 199 overall and in the slowest $10 \%$ of responses. There was also a significant increase in the number 200 of lapses. However, SD of the reciprocal reaction time was not significantly affected and there

201 was a marginally significant increase in the number of false starts after SR.

202 Table 2. PVT results - means and standard error of the mean.

\section{3.3. Attentional Blink}

Repeated-measures ANOVA for T2|T1 accuracy revealed a significant main effect for lag,

$F(2.8,64.8)=32.29, p<.001, \eta_{\mathrm{p}}^{2}=.58$, but no significant interaction between condition and lag, 206 $F(4.7,107.1)=0.91, p=.497, \eta_{\mathrm{p}}^{2}=.04$, and no significant main effect of condition, $F(1,23)=$ $0.06, p=.814, \eta_{\mathrm{p}}{ }^{2}<.001$, see Figure 2

[INSERT FIGURE 2 ABOUT HERE]

\section{Study 1 Results and Discussion}

The hypothesis that (i) performance on the PVT would be impaired during sleep restriction

211 was supported, however the hypothesis that (ii) AB performance would be impaired during sleep

212 restriction was not supported, as accuracy appeared to be robust to the impact of sleep restriction. 
213 This counterintuitive finding challenges the assumption that all aspects of attention are equally

214 affected by sleep loss, which warrants further investigation. Consequently, a second study was

215 designed to investigate the possible neural underpinnings of the observed differential decrement

216 in performance, using EEG.

217 Specifically, Study 2 examined the neural underpinnings that are likely driving the

218 observed attentional changes after partial sleep restriction. Based on the available literature, it

219 was anticipated that sleepiness would correlate negatively with global alpha and positively with

220 central frontal theta (Strijkstra et al., 2003), whereas delta and theta spectral power were

221 expected to increase with sleep loss (Hoedlmoser et al., 2011). Thus, it was hypothesised that

222 neural oscillations at rest will be related to the particular sleep condition and performance

223 measures will replicate those observed in Study 1, i.e. (i) PVT performance will be impaired

224 during sleep restriction, and (ii) AB performance will be unimpaired.

225 5. Study 2 Method

226 5.1. Participants

227 Twenty-four new participants ( 15 female; $M_{\text {age }}=24.8$ years, $\left.S D=6.8\right)$ were recruited at 228 the Australian National University (ANU) using Sona participant recruitment software, social 229 media, and word of mouth. The same study inclusion and exclusion criteria were employed as in 230 Study 1. Additionally, individuals were excluded if EEG might be unadvisable (e.g. recent head 231 injury, history of seizures, etc.). The same informed written consent procedures were used as in

232 Study 1. All participants received AUD\$30 upon completion. The study was conducted with full 233 ethics approval from the ANU HREC (Protocol \#2015/184). 


\section{5.2. Design and Procedure}

235 A repeated-measures design was used. Participants completed two EEG testing sessions in 236 counterbalanced order: (i) one after a normal night's sleep, and (ii) one after 5 hours' sleep; and

237 the sessions were one week apart. Participants were asked to arrive at the testing session at

238 13:00h, allowing 60 minutes to set up, so that they commenced the tasks at 14:00h.

As a stronger test for compliance with the sleep instructions, participants were provided with a FitBit ${ }^{\circledR}$ Charge HR (Diaz et al., 2015; Montgomery-Downs, Insana, \& Bond, 2012) at least three days prior to the first EEG testing session, and they were instructed to wear it for the

242 duration of the study. Additionally, they kept sleep diary estimates of sleep onset, morning

243 wakening, and rising times. Although actigraphy is not as reliable as polysomnography at

244 determining wake times (Quante et al., 2018), this provided an additional objective measure to 245 supplement the sleep diary estimates and ensure participants complied with the instructions. As

246 in Study 1, in the sleep restriction condition all participants were asked to delay their bedtime by

2473 hours, and to set their alarm for 5 hours later. FitBit ${ }^{\circledR}$ data was assessed using Fitabase ${ }^{\circledR}$

248 software (Diaz et al., 2015). Data for the three nights of sleep prior to the testing days were used 249 to confirm that the participants typically slept for 7-8 hours.

At 14:00h on both testing days, participants completed the KSS to assess their subjective

251 sleepiness. All study tasks were conducted in a dark room to avoid peripheral distractions, and

252 the researcher was absent from the room during testing. At the start of testing, they completed a

253 brief exercise to ensure that eye movements were accurately detected, enabling their removal

254 from further analysis. This involved moving eyes up, down, left, right, and blinking on cue.

255 Participants then completed the resting state exercise in which they were instructed to rest quietly

256 for two minutes with their eyes open, and for two minutes with their eyes closed. After this, they 
257 completed the AB and PVT tasks. The order of the tasks was counterbalanced across the

258 participants but it was consistent between the sessions. After completing the second EEG

259 session, participants were verbally debriefed and given an opportunity to withdraw their data

260 from the study, if they wished.

\section{5.3. Apparatus}

262 5.3.1. FitBit巴

263

As an objective measure to supplement sleep diaries, participants were asked to wear

264 FitBit ${ }$ Charge HR activity monitoring devices for three days prior to each of the two EEG 265 sessions.

\subsection{2. $E E G$}

A Compumedics NuAmps 40 channel EEG system was used to record

268 electrophysiological activity. Electrodes were positioned according to the 10/20 system (Jasper, 269 1958), which has become the international standard in EEG research (Jurcak, Tsuzuki, \& Dan,

270 2007). The reference electrode was placed centrally at CZ. Mastoid electrodes were placed

271 behind each ear, and eye movements (horizontal and vertical) were monitored by

272 Electrooculogram (EOG) electrodes. QuikGel ${ }^{\circledR}$ Electrolyte conductive solution was used to

273 establish a connection between the epidermis and electrodes. To ensure a strong connection, 274 impedance levels were set below $5 \mathrm{k} \Omega$. Signals were amplified and recorded using the NuAmps 275 digital amplifier at a sample rate of $1000 \mathrm{~Hz}$ for offline analysis using Curry 7.0.9 by

276 Compumedics Neuroscan, on Windows 7.

\section{5.3.3. Other Equipment}

278 Stimuli were presented on a 23.6-inch VIEWPixx liquid crystal display monitor with a 279 refresh rate of $120 \mathrm{~Hz}$ and a resolution of $1920 \times 1080$ pixels. Behavioural responses for the PVT 
280 were collected using a RESPONSEPixx VPX-ACC-3100 five-button response box. Behavioural 281 responses for the $\mathrm{AB}$ were collected using a Cedrus $\mathrm{RB}-830$ response pad, with buttons labelled 282 2-9.

283 5.4. Stimuli

284 Experimental stimuli were created using Psychophysics Toolbox version 3.0.12 (Brainard, 285 1997; Pelli, 1997) for MATLAB version R2012b.

286 5.4.1.PVT

287 PVT presentations replicated the approach used in Study 1, but inter-stimulus interval 288 length varied from $2-10$ seconds.

289 5.4.2. $A B$

290 AB task presentation replicated the approach used in Study 1, but fewer lags were 291 assessed, to permit more repetitions of each lag. T2 was presented at a lag of 1, 3, 5 or 8 stimuli 292 after T1. Each AB trial consisted of 18-22 items, including two targets. T1 was presented with 293 jitter of \pm 2 items, meaning that T1 appeared after 4-8 distractors. Items were presented in 294 Helvetica font.

Prior to the first test session, participants were given 12 practice trials at half speed,

296 followed by 12 practice trials at full speed. During the second test session, they were given 12 297 practice trials at full speed. Auditory accuracy feedback was provided after each practice trial. 298 Following the practice blocks, 50 trials were included for each lag, resulting in a total of 299200 trials per session. Rest breaks were offered after every 50 trials, with the duration decided by 300 participants. The AB task took approximately 10 minutes to complete, excluding breaks. 
301

302

303

304

305

306

307

308

309

310

311

312

313

314

315

316

317

318

319

320

321

322

323

\subsubsection{Subjective Sleepiness}

Subjective sleepiness was assessed using the KSS, this time administered once at 14:00h in both sessions.

\subsection{EEG Data Analysis}

EEG analysis focused on the data gathered during the eyes-closed resting state conducted before the experimental tasks, hereto forth referred to as the resting-state. This decision was made to minimise artefacts in the data relating to eye movements. Resting state data were compared between sleep conditions. EEG data recorded during the eyes-closed resting state was useable in all cases. Analysis was achieved by isolating the desired epoch from the EEG data, which was then visually inspected for anomalous artefacts (e.g. jaw clenches, blinks, electrode pops, etc.), which were removed from further analysis. Data were baseline corrected, rereferenced offline to the common average reference, and filtered with a bandpass IIR filter between $0.5-47 \mathrm{~Hz}$ to remove drift and high-frequency artefacts. Only eyes-closed resting state data from 14-104 seconds were used, which eliminated muscle artefacts from closing the eyes. Electrodes were grouped into regions of interest (ROI) based on hemisphere (left and right) and scalp location (frontal, central and occipital; see Table 3). Alpha power was determined as the average power across frequencies between $8-12 \mathrm{~Hz}$; delta power as $0.5-4 \mathrm{~Hz}$; and theta power as 4-8 Hz.

Spectral power for the resting state was calculated for each channel using a sliding 2second window with .75 overlap; each sample was windowed with a Hamming window to avoid edge effects, and power was extracted using a fast Fourier transform. Relative power was computed by dividing the relevant spectral band by the sum of all spectral bands for that individual (Delorme \& Makeig, 2004; Stoica \& Moses, 1997, 2005). For each channel, the 
324 average power across all frequencies was calculated to produce an average amplitude spectrum.

325 Spectral analysis was conducted using EEGLAB Version 13.4.4 (Delorme \& Makeig, 2004) for

326 MATLAB R2015a.

327 Table 3. Regions of interest and corresponding electrode groupings.

\section{5.6. Statistical Analysis}

329 All statistical analyses were conducted using SPSS Version 23. EEG data were analysed

330 using repeated-measures ANOVA. The factors used in the ANOVA were the 6 ROI's and the

331 sleep condition (NS or SR). ANOVAS were conducted for alpha, theta, and delta frequencies.

332 Means were compared (paired-samples $t$-tests and non-parametric tests) to determine whether

333 sleep condition caused a significant difference in relative and absolute spectral power. FitBit ${ }^{\text {, }}$

334 sleep journal, and KSS data were analysed using two-tailed paired-samples $t$-tests. In the event of

335 skewed data, non-parametric tests were used.

336 Correlational analysis determined the most representative measure of attention

337 performance in the PVT data, and paired-samples $t$-tests were used to determine if performance

338 was affected by the sleep condition.

339 In assessing the $\mathrm{AB}$ data, non-parametric tests determined whether blink magnitude and

340 performance for lags $1,3,5$, and 8 differed significantly in the two conditions. AB magnitude

341 was calculated by subtracting each participant's T2|T1 accuracy at lag 3 from their T2|T1

342 accuracy at lag 8 (MacLean et al., 2012). 


\section{6. Study 2 Results}

\section{6.1. Sleep Characteristics}

345 FitBit ${ }^{\circledR}$ data were inspected to ensure that participants: (i) habitually slept 7-9h, (ii)

346 achieved sufficient sleep in the NS condition ( $\geq 7$ hours), and (iii) genuinely restricted their sleep

347 ( $\leq 5$ hours). Two cases were excluded on the basis of criterion (iii), and one was excluded due to

348 criterion (i), leaving 21 valid cases. The PVT data was inspected for univariate and multivariate

349 outliers using the procedures outlined by Tabachnick and Fidell (2013).

$350 \quad$ Sleep diary and FitBit ${ }^{\circledR}$ were visually inspected and tested for normality using the Shapiro-

351 Wilk test. All variables met assumptions of normality, except SR sleep diary reports, $W(21)=$

$352.59, p<.001$, which is likely due to restriction of range (participants were instructed to sleep for

353 exactly 5 hours). Consequently, Wilcoxon Signed Rank Tests were used in all the analyses

354 involving the SR diary reports. A Bonferroni-adjusted alpha level of 0.013 was used to reduce

355 the likelihood of Type-I errors.

356 FitBit ${ }^{\circledR}$ data showed a significant difference between NS $(M=8.2$ hours, $S D=0.9)$, and

357 SR $(M=4.64$ hours, $S D=0.44)$ conditions, $t(20)=15.70, p<.001 ; d=3.43,99 \% \mathrm{CI}[2.01$,

358 4.89]. Similarly, there was a significant difference between the diary reports of sleep duration

359 during NS (median $=8.5$ hours) and SR (median $=5$ hours) conditions, $Z=-2.43, p=.015, r=$ -

360 0.53. Results indicate that participants were genuinely restricting their sleep.

361 To test whether participants were accurately recording sleep, FitBit ${ }^{\circledR}$ data were compared

362 with sleep diary estimates (see Figure 3). No significant difference was found between the

363 FitBit $\AA$ data $(M=8.2, S D=0.9)$ and diary reports $(M=8.3, S D=1.0)$ in the NS condition, $t(20)$

$364=-0.52, p=.606 ; d=-0.11,99 \%$ CI $[0, .64]$. However, there was a significant difference 
365 between FitBit ${ }^{\circledR}($ median $=4.5)$ and diary $($ median $=5.0)$ data in the SR condition, $Z=-4.02, p<$ $366.001, r=-0.88$.

\subsection{Subjective Sleepiness}

For KSS data, one multivariate outlier was detected using Mahalanobis distance $(46.80, p$

$<.001)$. This case did not report a change in sleepiness between sessions, indicating that the experimental manipulation had not affected their subjective sleepiness. KSS scores in the NS normality, $W(21)=.79, p<.001$. Visual inspection of the data determined that the identified and excluded. As the overall outcome was unaffected, the anomalous participant's data were retained. As visual inspection revealed that the distribution of the data was only marginally

377 skewed, parametric and non-parametric tests were performed to compare the means. As the

378 overall outcomes did not differ, only the results for the paired-samples $t$-test are reported here.

379 A paired-samples $t$-test determined that the KSS ratings differed significantly between NS

$380(M=4.0, S D=1.8)$ and $\mathrm{SR}(M=6.9, S D=1.5)$ conditions; $t(20)=-7.83, p<.001 ; d=-1.71$,

$38195 \%$ CI $[1.02,2.38]$. Results suggest that the experimental condition significantly increased 382 perceived sleepiness; see Figure 4a.

\section{6.3. Main analyses}

384 6.3.1. Behavioural data (AB \& PVT)

$$
\text { 6.3.1.1. PVT }
$$


388 not affect the analysis, so they were retained. False starts, lapses, mean fastest $10 \%$ of RTs, mean

389 slowest $10 \%$ of RTs, median RT, SD of RT, skew, mean RT, errors of omission, errors of

390 commission and number of trials were recorded for each PVT session. Pearson product-moment

391 correlation coefficients were computed to determine which measure of PVT performance was

392 most representative of overall performance. Mean RT was most highly correlated with the other

393 measures, indicating that it was the most representative measure of overall PVT performance.

394 Mean RT was statistically and visually inspected for normality. Assumptions of normality were

395 met. A paired-samples $t$-test determined that mean RT was significantly lower in the NS $(M=$

$396285 \mathrm{~ms}, S D=0.03)$ than the SR $(M=298 \mathrm{~ms}, S D=0.03)$ condition, $t(20)=-2.49, p=.022, d=$

$3970.54,95 \%$ CI $[0.09,0.99]$; see Figure $4 b$.

398

399

400

401

402

403

404

405

406

407

408

409

410

411

\subsubsection{2. $A B$}

\section{[INSERT FIGURE 4 ABOUT HERE]}

AB data were skewed; thus, non-parametric tests were conducted. Wilcoxon signed-rank tests, with a Bonferroni-adjusted alpha level of 0.013 , showed that accuracy at each lag did not differ significantly in the NS and SR conditions. Wilcoxon signed-rank tests for NS and SR are displayed in Table 4. Mean proportion of correct responses per lag are displayed graphically in

Figure 4. Additionally, a Wilcoxon signed-rank test indicated no significant difference between the blink magnitude in the NS (median $=.13)$ and SR $($ median $=.10)$ conditions; $\mathrm{Z}=-.99, p=$ $.322, r=-0.22$. The results are illustrated in Figure 5 .

Table 4. Wilcoxon signed-rank test results for lags in NS and SR conditions.

\subsubsection{EEG Data Analysis}

[INSERT FIGURE 5 ABOUT HERE]

To reduce extreme skewness and kurtosis, absolute spectral power for alpha, delta, and theta bands were logarithmically transformed. Relative spectral power was normally distributed 
412 across all the frequency bands. One-way repeated measures ANOVA was used for all

413 comparisons.

414

415

416

417

418

419

420

421

422

\subsubsection{Theta}

No significant difference was found between the sleep conditions in theta spectral power $F(1,20)=1.91, p=.183 ; \eta_{\mathrm{p}}{ }^{2}=.06,95 \%$ CI $[0.00,0.30]$ or relative power $F(1,20)=1.05, p=$ $.317 ; \eta_{\mathrm{p}}^{2}=.05,95 \%$ CI $[0.00,0.29]$

\subsubsection{Alpha}

A significant effect of sleep condition was detected for alpha spectral power, $F(1,20)=$ $8.18, p=.010 ; \eta_{\mathrm{p}}{ }^{2}=.29,95 \% \mathrm{CI}[.02, .53]$. When ROIs were considered separately, the only difference to reach statistical significance (using a Bonferroni-adjusted alpha level of .008) was log of alpha in the central left and right hemisphere. Results indicate that there was a significant reduction in central spectral alpha across both hemispheres in the SR condition; see Table 5.

Table 5. Results of paired-samples t-tests for log of absolute and relative spectral alpha.

There was also a significant effect of sleep condition on relative alpha power, $F(1,20)=$ $5.47, p=.030 ; \eta_{\mathrm{p}}{ }^{2}=0.22,95 \% \mathrm{CI}[0.00, .47]$. When the results for ROIs were considered separately, the only difference to reach statistical significance was relative alpha in the central right hemisphere. Results indicate that there was a significant reduction in relative alpha spectral power in the central right hemisphere in the SR condition; see Table 5.

\subsubsection{Delta}

There was no significant effect of sleep condition on delta spectral power, $F(1,20)=.53, p$ $=.475 ; \eta_{\mathrm{p}}^{2}=.03,95 \%$ CI $[0.00,0.25]$ 
A marginally significant effect of sleep was detected for relative delta power, $F(1,20)=$

$3.86, p=.063 ; \eta_{\mathrm{p}}^{2}=.16,95 \%$ CI $[0.00,0.42]$. When ROIs were considered separately, the only

hemisphere. Results indicate that a moderate increase of relative delta spectral power occurred in

the central right hemisphere in the SR condition; see Table 6.

Table 6. Results of paired-samples t-tests for relative spectral delta.

\subsubsection{Analysis of Alpha and Delta}

Figure 6 illustrates comparative changes in relative resting state frequency for alpha and

regional locations of these changes.

\section{[INSERT FIGURES 6 \& 7 ABOUT HERE]}

\subsubsection{Individual Change in Alpha and Delta}

Individual changes in relative alpha and delta were analysed for the right central region,

where the most significant changes in activity were observed, to determine if the individual changes in spectral power were related to the performance and questionnaire measures. Change 

changes in spectral power (left), and changes in subjective sleepiness and changes in spectral

460 power (right). Alpha change and RT change were moderately negatively correlated, $r(20)=-$

$4610.49, p=.023$, suggesting that a greater reduction in individual right central alpha during sleep

462 restriction corresponded to a greater increase in RT in individuals. Delta change and RT change

463 were moderately positively correlated, $r(20)=0.42, p=.057$, suggesting that a greater increase

464 in individual right central delta during sleep restriction corresponded to a greater increase in RT

465 in individuals. Alpha change and KSS change were strongly negatively correlated, $r(20)=-0.51$,

$466 p=.019$, suggesting that greater individual reduction in right central alpha during sleep

467 restriction corresponded to greater increase in reported subjective sense of sleepiness in

468 individuals. Similarly, delta change and KSS were positively correlated, $r(20)=.0 .52, p=.015$,

469 suggesting that a greater increase in individual delta corresponded with a greater increase of

470 reported subjective sleepiness in individuals.

471

472

473

474

475

476

477

478

479

480

\section{General Discussion}

Studies 1 and 2 detected consistent differences between the PVT and AB tasks.

Specifically, performance on the PVT was reduced during the sleep restriction condition, whereas performance on the AB task was unimpaired. In addition, the hypothesis that neural oscillations at rest would be related to sleep condition was supported. Alpha oscillations were significantly reduced during the sleep restriction condition; in particular, centrally in the right hemisphere. The results support the findings of Strijkstra et al. (2003) who found that alpha reduced as sleepiness increased. Overall, delta oscillations were not significantly different between sleep conditions, although a marginally significant increase in delta oscillation was observed in the central right hemisphere. As this was the same area where a reduction in alpha 
481 oscillations occurred, it is possible that slow wave delta activity superseded the alpha oscillations

482 in the central right hemisphere during sleep restriction. The absence of a significant difference in

483 either theta or delta oscillations might be attributable to the study participants experiencing sleep

484 restriction rather than total sleep deprivation, especially as changes in delta have been

485 consistently found in previous literature (e.g. Cajochen et al., 1999; Hoedlmoser et al., 2011;

486 Strijkstra et al., 2003).

487 Two interpretations may account for the preservation of performance accuracy on the $\mathrm{AB}$

488 task during the sleep restriction condition. First, transient attention may be more robust to the

489 effects of sleep reduction than sustained attention. Research conducted by Shenfield, Beanland

490 and Apthorp (2020) suggested that the PVT and AB tasks have similar levels of engagement and

491 difficulty, which suggests that sleep loss is unlikely to be interacting with different levels of

492 difficulty between the two tasks. Thus, it is proposed that preserved AB performance relative to

493 PVT performance during sleep loss is more likely attributable to differences in the cognitive

494 requirements of the discrete forms of attention required for each task (Braver, Reynolds, \&

495 Donaldson, 2003; Carrasco, 2011). If this is the case, the studies highlight the need for future

496 research to better understand the impact of sleep loss on discrete forms of attention.

497 The second potential explanation relates to the reduction in alpha after sleep restriction,

498 which may have prevented a performance decrement on the AB task. This interpretation is

499 supported by previous research which found that lower levels of alpha were associated with

500 better AB performance (MacLean \& Arnell, 2011; MacLean et al., 2012). It has been suggested

501 that alpha amplitude may interact with the RSVP task specifically, as the stimuli are typically

502 displayed at a rate of $100 \mathrm{~ms}$, which is analogous to the $10 \mathrm{~Hz}$ oscillations characteristic of alpha

503 waves (Mathewson et al., 2011). Based on this assertion, Zauner et al. (2012) proposed that alpha 
504 entrainment occurs during the $\mathrm{AB}$, whereby the amplitude of alpha oscillations either facilitates

505 or prohibits the detection of the second target; and they found that alpha amplitude was larger on

506 the trials when an $\mathrm{AB}$ was present (i.e. when $\mathrm{T} 1$ but not $\mathrm{T} 2$ was perceived). Conversely, when

507 alpha amplitude was smaller, they detected a considerable reduction in AB. The analysis of EEG

508 activity during the $\mathrm{AB}$ task, as opposed to during a resting state, would be required to provide

509 further support for this theory.

510 While it is not currently possible to confirm or disconfirm either potential explanation,

511 both of them equally challenge traditional assertions about sleep loss, which propose that

512 attention is a single construct that is reliably impaired during sleep restriction. The findings

513 presented here expand on current knowledge regarding sleep, which has previously focused on

514 measuring neural activity during sleep deprivation (Borbély et al., 1981; Kaida et al., 2006), as

515 opposed to sleep restriction. This distinction is important, as total sleep deprivation occurs

516 irregularly, and is arguably more representative of a crisis-type situation, whereas sleep loss is

517 relatively common, either consistent or intermittent, due to a person's lifestyle, social and

518 occupational obligations, or physical and mental health conditions (Banks \& Dinges, 2007;

519 Knutson et al., 2010; Tucker, Dinges, \& Van Dongen, 2007). Additionally, this finding has

520 important clinical implications for the non-pharmacological treatment of patients who experience

521 disordered sleep. For example, traditional therapeutic interventions addressing sleep (e.g. sleep

522 hygiene, cognitive behavioural therapy, etc.) require clients to employ sustained attention, which

523 has reliably been found to be compromised during sleep loss (Lim \& Dinges, 2008; Stepanski \&

524 Wyatt, 2003). The current findings show that sleep loss interventions may be most effective

525 when brief and focused, to better cater to preserved transient attention capacity. These findings

526 also reinforce the importance of safety precautions for tasks which may require sustained 
527 attention during sleep loss (e.g. driving; Beanland, Filtness, Larue, \& Hawkins, 2016; Philip et

528 al., 2005).

\section{7.1. Conclusion}

530 Two studies found that performance on a sustained attention task (the PVT) was impaired

531 during sleep restriction; however, performance on a transient attention task (the $\mathrm{AB}$ ) was

532 unimpaired. EEG activity indicated that differences in neural oscillations, specifically a

533 reduction in right central alpha and an increase in right central delta after sleep restriction, might

534 be driving the observed difference in impairment between the tasks. Both studies detected

535 compelling evidence for the preservation of a discrete form of attention (i.e. transient attention)

536 during sleep restriction. This finding challenges the notion that attention is impacted as a singular

537 construct under conditions of sleep loss, highlighting the possibility that other forms of attention

538 might be robust to the impact of sleep loss. Ideally, the results of this research should shape the

539 way in which findings regarding sleep and attention are expressed in future research, to more

540 accurately describe and investigate the individual components of attention which are being tested

541 and impacted.

542

543 9. Acknowledgements

544 The authors thank Mille Darvell, Luke Daly and Adrian Wilson for their assistance in data

545 collection for Study 1. Thank you to Dr Rhonda Brown for her assistance in editing and proof

546 reading stages. 
549

550

551

552

553

554

555

556

557

558

559

560

561

562

563

564

565

566

567

568

569

570

571

572

573

574

575

576

577

\section{References}

Åkerstedt, T., \& Gillberg, M. (1990). Subjective and objective sleepiness in the active individual. International Journal of Neuroscience, 52, 29-37. doi:10.1016/S0022-3999(02)00333-1

American Academy of Sleep Medicine. (2014). International Classification of Sleep Disorders Third Edition (ICSD-3). IL, USA: American Academy of Sleep Medicine.

American Psychiatric Association. (2013). Diagnostic and statistical manual of mental disorders (5th ed.). Arlington, VA: American Psychiatric Publishing.

Antonenko, P., Paas, F., Grabner, R., \& van Gog, T. (2010). Using electroencephalography to measure cognitive load. Educational Psychology Review, 22(4), 425-438. doi:10.1007/s10648-010-9130-y

Ayalon, L., Ancoli-Israel, S., Aka, A. A., McKenna, B. S., \& Drummond, S. P. A. (2009). Relationship between obstructive sleep apnea severity and brain activation during a sustained attention task. Sleep, 32(3), 373-381.

Banks, S., \& Dinges, D. F. (2007). Behavioral and physiological consequences of sleep restriction. Journal of Clinical Sleep Medicine, 3(5), 519-528.

Basner, M., \& Dinges, D. F. (2011). Maximizing Sensitivity of the Psychomotor Vigilance Test (PVT) to Sleep Loss. Sleep, 34(5), 581-591.

Beanland, V., Filtness, A. J., Larue, G. S., \& Hawkins, A. (2016). Effects of sleep loss on change detection while driving. In. Canberra, ACT: NRMA-ACT Road Safety Trust.

Benca, R. M., Obermeyer, W. H., Larson, C. L., Yun, B., Dolski, I., Kleist, K. D., . . Davidson, R. J. (1999). EEG alpha power and alpha power asymmetry in sleep and wakefulness. Psychophysiology, 36, 430-436.

Berka, C., Levendowski, D. J., Lumicao, M. N., Yau, A., Davis, G., Zivkovic, V. T., ... Craven, P. L. (2007). EEG correlates of task engagement and mental workload in vigilance, learning, and memory tasks. Aviation, Space, and Environmental Medicine, 78(Supplement 1), B231-B244.

Boonstra, T. W., Daffertshofer, A., \& Beek, P. J. (2005). Effects of sleep deprivation on eventrelated fields and alpha activity during rhythmic force production. Neuroscience Letters, 388(1), 27-32. doi:10.1016/j.neulet.2005.06.045 
578 Borbély, A. A., Baumann, F., Brandeis, D., Strauch, I., \& Lehmann, D. (1981). Sleep

579

580

581

582

583

584

585

586

587

588

589

590

591

592

593

594

595

596

597

598

599

600

601

602

603

604

605

606

607 deprivation: Effect on sleep stages and EEG power density in man. Electroencephalography and Clinical Neurophysiology, 51(5), 483-493.

Brainard, D. H. (1997). The psychophysics toolbox. Spatial Vision, 10, 433-436.

Braver, T. S., Reynolds, J. R., \& Donaldson, D. I. (2003). Neural mechanisms of transient and sustained cognitive control during task switching. Neuron, 39(4), 713-726.

Broadbent, D. E., \& Broadbent, M. H. (1987). From detection to identification: Response to multiple targets in rapid serial visual presentation. Perception \& Psychophysics, 42(2), 105-113.

Cajochen, C., Foy, R., \& Dijk, D.-J. (1999). Frontal predominance of a relative increase in sleep delta and theta EEG activity after sleep loss in humans. Sleep Research Online, 2(3), 6569.

Capotosto, P., Babiloni, C., Romani, G. L., \& Corbetta, M. (2009). Frontoparietal cortex controls spatial attention through modulation of anticipatory alpha rhythms. The Journal of Neuroscience, 29(18), 5863-5872.

Carrasco, M. (2011). Visual attention: the past 25 years. Vision Research, 51(13), 1484-1525. doi:10.1016/j.visres.2011.04.012

Deloitte Access Economics. (2011). Re-awakening Australia: The economic cost of sleep disorders in Australia. Retrieved from https://www.sleephealthfoundation.org.au/pdfs/news/Reawakening\%20Australia.pdf

Delorme, A., \& Makeig, S. (2004). EEGLAB: An open source toolbox for analysis of single-trial EEG dynamics including independent component analysis. Journal of Neuroscience Methods, 134(1), 9-21. doi:10.1016/j.jneumeth.2003.10.009

Diaz, K. M., Krupka, D. J., Chang, M. J., Peacock, J., Ma, Y., Goldsmith, J., . . Davidson, K.

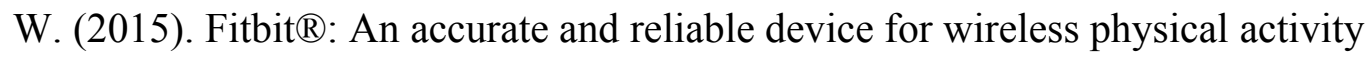
tracking. International Journal of Cardiology, 185, 138-140. doi:10.1016/j.ijcard.2015.03.038

Dinges, D. F., \& Powell, J. W. (1985). Microcomputer analyses of performance on a portable, simple visual RT task during sustained operations. Behavior Research Methods, Instruments, \& Computers, 17(6), 652-655. 
608 Drummond, S. P. A., Amanda Bischoff-Grethe, A., Dinges, D. F., Liat Ayalon, L., Mednick, S.

609

610

611

612

613

614

615

616

617

618

619

620

621

622

623

624

625

626

627

628

629

630

631

632

633

634

635

636

637

638

C., \& Meloy, M. J. (2005). The neural basis of the psychomotor vigilance task. Sleep, 8(29), 1059-1068.

Dux, P., \& Marois, R. (2009). The attentional blink: A review of data and theory. Attention, Perception, \& Psychophysics, 71(8), 1683-1700. doi:10.3758/APP.71.8.1683

Ergenoglu, T., Demiralp, T., Bayraktaroglu, Z., Ergen, M., Beydagi, H., \& Uresin, Y. (2004). Alpha rhythm of the EEG modulates visual detection performance in humans. Cognitive Brain Research, 20(3), 376-383. doi:10.1016/j.cogbrainres.2004.03.009

Händel, B. F., Haarmeier, T., \& Jensen, O. (2011). Alpha oscillations correlate with the successful inhibition of unattended stimuli. Journal of Cognitive Neuroscience, 23(9), 2494-2502. doi:10.1162/jocn.2010.21557

Hanslmayr, S., Gross, J., Klimesch, W., \& Shapiro, K. L. (2011). The role of alpha oscillations in temporal attention. Brain Research Reviews, 67(1-2), 331-343. doi:10.1016/j.brainresrev.2011.04.002

Harmony, T., Fernández, T., Silva, J., Bernal, J., Díaz-Comas, L., Reyes, A., . . Rodríguez, M. (1996). EEG delta activity: An indicator of attention to internal processing during performance of mental tasks. International Journal of Psychophysiology, 24(1), 161-171. doi:10.1016/S0167-8760(96)00053-0

Hirshkowitz, M., Whiton, K., Albert, S. M., Alessi, C., Bruni, O., DonCarlos, L., ... Adams Hillard, P. J. (2015). National Sleep Foundation's sleep time duration recommendations: methodology and results summary. Sleep Health, 1(1), 40-43. doi:10.1016/j.sleh.2014.12.010

Hoedlmoser, K., Griessenberger, H., Fellinger, R., Freunberger, R., Klimesch, W., Gruber, W., \& Schabus, M. (2011). Event-related activity and phase locking during a psychomotor vigilance task over the course of sleep deprivation. Journal of Sleep Research, 20(3), 377-385. doi:10.1111/j.1365-2869.2010.00892.x

Ibáñez, V., Silva, J., \& Cauli, O. (2018). A survey on sleep assessment methods. PeerJ, 6, e4849. doi:10.7717/peerj.4849

Jasper, H. H. (1958). Report of the committee on methods of clinical examination in electroencephalography: 1957. Electroencephalography and Clinical Neurophysiology, 10(2), 370-375. doi:10.1016/0013-4694(58)90053-1

Peer) reviewing PDF | (2019:10:42310:2:0:NEW 16 Mar 2020) 
639 Jurcak, V., Tsuzuki, D., \& Dan, I. (2007). 10/20, 10/10, and 10/5 systems revisited: Their 640 validity as relative head-surface-based positioning systems. NeuroImage, 34(4), 16001611. doi:10.1016/j.neuroimage.2006.09.024

642 Kaida, K., Takahashi, M., Åkerstedt, T., Nakata, A., Otsuka, Y., Haratani, T., \& Fukasawa, K. 643

644 (2006). Validation of the Karolinska Sleepiness Scale against performance and EEG

645 variables. Clinical Neurophysiology, 117(7), 1574-1581.

646 doi:10.1016/j.clinph.2006.03.011

Kirschfeld, K. (2008). Relationship between the amplitude of $\alpha$ waves and reaction time. NeuroReport, 19(9), 907-910. doi:10.1097/WNR.0b013e328302c545

Klimesch, W. (1999). EEG alpha and theta oscillations reflect cognitive and memory performance: a review and analysis. Brain Research Reviews, 29, 169-195. doi:10.1016/S0165-0173(98)00056-3

Knutson, K. L., Van Cauter, E., Rathouz, P. J., DeLeire, T., \& Lauderdale, D. S. (2010). Trends in the prevalence of short sleepers in the USA: 1975-2006. Sleep, 33(1), 37-45.

Langner, R., \& Eickhoff, S. B. (2013). Sustaining attention to simple tasks: A meta-analytic review of the neural mechanisms of vigilant attention. Psychological Bulletin, 139(4), 870-900. doi:10.1037/a0030694

Lenné, M. G., Triggs, T. J., \& Redman, J. R. (1997). Time of day variations in driving performance. Accident Analysis \& Prevention, 49(4), 431-437. doi:10.1016/S00014575(97)00022-5

Lim, J., \& Dinges, D. F. (2008). Sleep deprivation and vigilant attention. Annals of the New York Academy of Sciences, 1129(1), 305-322. doi:10.1196/annals.1417.002

Lim, J., \& Dinges, D. F. (2010). A meta-analysis of the impact of short-term sleep deprivation on cognitive variables. Psychological Bulletin, 136(3), 375-389. doi:10.1037/a0018883

Liu, T., Pestilli, F., \& Carrasco, M. (2005). Transient attention enhances perceptual performance and fMRI response in human visual cortex. Neuron, 45(3), 469-477. doi:10.1016/j.neuron.2004.12.039

Maclean, M. H., \& Arnell, K. M. (2011). Greater attentional blink magnitude is associated with higher levels of anticipatory attention as measured by alpha event-related desynchronization (ERD). Brain Research, 1387, 99-107. doi:10.1016/j.brainres.2011.02.069 
670 MacLean, M. H., Arnell, K. M., \& Cote, K. A. (2012). Resting EEG in alpha and beta bands

671

672

673

674

675

676

677

678

679

680

681

682

683

684

685

686

687

688

689

690

691

692

693

694

695

696

697

698

699 predicts individual differences in attentional blink magnitude. Brain and Cognition, 78(3), 218-229. doi:10.1016/j.bandc.2011.12.010

Mathewson, K. E., Lleras, A., Beck, D. M., Fabiani, M., Ro, T., \& Gratton, G. (2011). Pulsed out of awareness: EEG alpha oscillations represent a pulsed-inhibition of ongoing cortical processing. Frontiers in Psychology, 2, 99. doi:10.3389/fpsyg.2011.00099

Matricciani, L., Olds, T., \& Williams, M. (2011). A review of evidence for the claim that children are sleeping less than in the past. Sleep, 34(5), 651-659.

Montgomery-Downs, H. E., Insana, S. P., \& Bond, J. A. (2012). Movement toward a novel activity monitoring device. Sleep and Breathing, 16(3), 913-917. doi:10.1007/s11325011-0585-y

Oken, B. S., Salinsky, M. C., \& Elsas, S. M. (2006). Vigilance, alertness, or sustained attention: Physiological basis and measurement. Clinical Neurophysiology, 117(9), 1885-1901. doi:10.1016/j.clinph.2006.01.017

Owens, J. A. (2009). A clinical overview of sleep and attention-deficit/hyperactivity disorder in children and adolescents. Journal of the Canadian Academy of Child and Adolescent Psychiatry, 18(2), 92-102.

Pelli, D. G. (1997). The VideoToolbox software for visual psychophysics: Transforming numbers into movies. Spatial Vision, 10(4), 437-442.

Philip, P., Sagaspe, P., Moore, N., Taillard, J., Charles, A., Guilleminault, C., \& Bioulac, B. (2005). Fatigue, sleep restriction and driving performance. Accident Analysis \& Prevention, 37(3), 473-478. doi:10.1016/j.aap.2004.07.007

Potter, M. C., \& Levy, E. I. (1969). Recognition memory for a rapid sequence of pictures. Journal of Experimental Psychology, 81(1), 10-15. doi:10.1037/h0027470

Quante, M., Kaplan, E. R., Cailler, M., Rueschman, M., Wang, R., Weng, J., Taveras, E. M., \& Redline, S. (2018). Actigraphy-based sleep estimation in adolescents and adults: A comparison with polysomnography using two scoring algorithms. Nature and Science of Sleep , 10, 13-20. https://doi.org/10.2147/NSS.S151085

Raz, A. (2004). Anatomy of attentional networks. The Anatomical Record Part B: The New Anatomist, 281B(1), 21-36. doi:10.1002/ar.b.20035 
700 Reynolds, A. C., \& Banks, S. (2010). Total sleep deprivation, chronic sleep restriction and sleep

701

702

703

704

705

706

707

708

709

710

711

712

713

714

715

716

717

718

719

720

721

722

723

724

725

726

727

728

729 disruption. Progress in brain research (185) 91-103. doi:10.1016/B978-0-444-537027.00006-3

Riccio, C. A., Reynolds, C. R., Lowe, P., \& Moore, J. J. (2002). The continuous performance test: A window on the neural substrates for attention? Archives of Clinical Neuropsychology, 17(3), 235-272. doi:10.1016/S0887-6177(01)00111-1

Shapiro, K. L., Raymond, J. E., \& Arnell, K. M. (1997). The attentional blink. Trends in Cognitive Sciences, 1(8), 291-296. doi:10.1016/S1364-6613(97)01094-2

Shenfield, L., Beanland, V. \& Apthorp, D. (2020). Temporal predictability does not impact attentional blink performance: Effects of fixed vs. random inter-trial intervals. PeerJ 8 e8677. https://doi.org/10.7717/peerj.8677

Stepanski, E. J., \& Wyatt, J. K. (2003). Use of sleep hygiene in the treatment of insomnia. Sleep Medicine Reviews, 7(3), 215-225. doi:10.1053/smrv.2001.0246

Steriade, M. (1999). Coherent oscillations and short-term plasticity in corticothalamic networks. Trends in Neurosciences, 22(8), 337-345. doi:10.1016/S0166-2236(99)01407-1

Stoica, P., \& Moses, R. L. (1997). Introduction to Spectral Analysis (Vol. 1). Upper Saddle River, NJ: Prentice Hall.

Stoica, P., \& Moses, R. L. (2005). Spectral analysis of signals. Upper Saddle River, NJ: Prentice Hall.

Strijkstra, A. M., Beersma, D. G. M., Drayer, B., Halbesma, N., \& Daan, S. (2003). Subjective sleepiness correlates negatively with global alpha $(8-12 \mathrm{~Hz})$ and positively with central frontal theta $(4-8 \mathrm{~Hz})$ frequencies in the human resting awake electroencephalogram. Neuroscience Letters, 340(1), 17-20. doi:10.1016/S0304-3940(03)00033-8

Suri, G., Sheppes, G., Leslie, S., \& Gross, J. J. (2014). Stairs or escalator? Using theories of persuasion and motivation to facilitate healthy decision making. Journal of Experimental Psychology: Applied, 20(4), 295-302. doi:10.1037/xap0000026

Tabachnick, B. G., \& Fidell, L. S. (2013). Using Multivariate Statistics (6 ed.). Boston, MA: Pearson.

Tong, S., \& Thakor, N. V. (2009). Quantitative EEG Analysis Methods and Clinical Applications: Artech House. 
730 Tucker, A. M., Dinges, D. F., \& Van Dongen, H. P. (2007). Trait interindividual differences in 731 the sleep physiology of healthy young adults. Journal of Sleep Research, 16(2), 170-180. doi:10.1111/j.1365-2869.2007.00594.x

Whitney, P., \& Hinson, J. M. (2010). Measurement of cognition in studies of sleep deprivation. In Progress in Brain Research (Vol. 185, pp. 37-48). Netherlands: Elsevier Science \& Technology.

Zauner, A., Fellinger, R., Gross, J., Hanslmayr, S., Shapiro, K. L., Gruber, W., . . Klimesch, W. (2012). Alpha entrainment is responsible for the attentional blink phenomenon. NeuroImage, 63(2), 674-686. doi:10.1016/j.neuroimage.2012.06.075

Zerouali, Y., Jemel, B., \& Godbout, R. (2010). The effects of early and late night partial sleep deprivation on automatic and selective attention: An ERP study. Brain Research, 1308, 742

743 
Figure 1

An illustration of the Attentional Blink

Eight frames of an RSVP stream in an AB task, depicting a lag of 3 between T1 and T2.

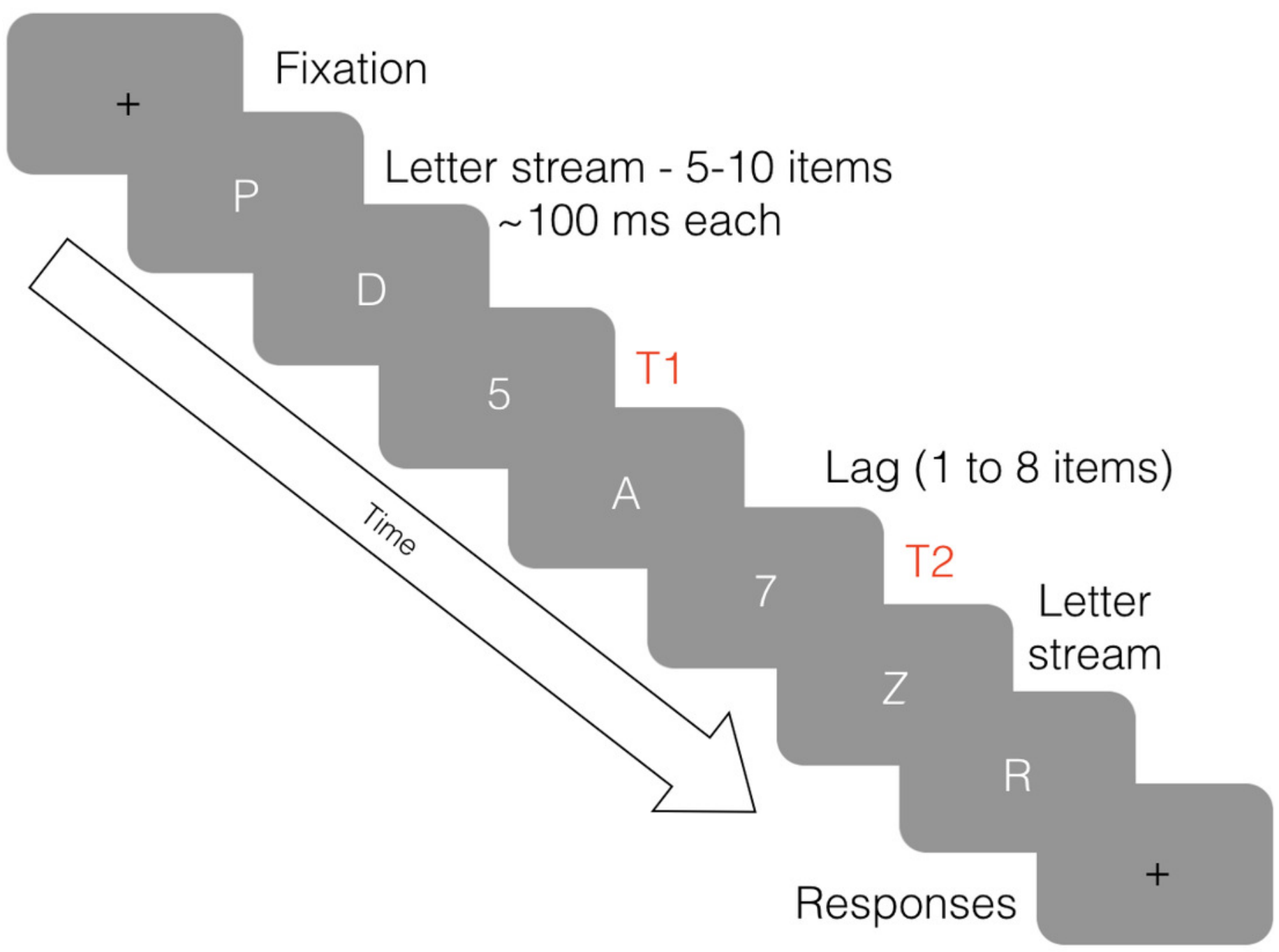


Figure 2

Experiment 1: Attentional blink performance in sleep restricted and normal sleep conditions

Results T2|T1 accuracy by lag for normal sleep (NS) and sleep restriction (SR) conditions. Error bars represent +/- 1 SE around the mean.

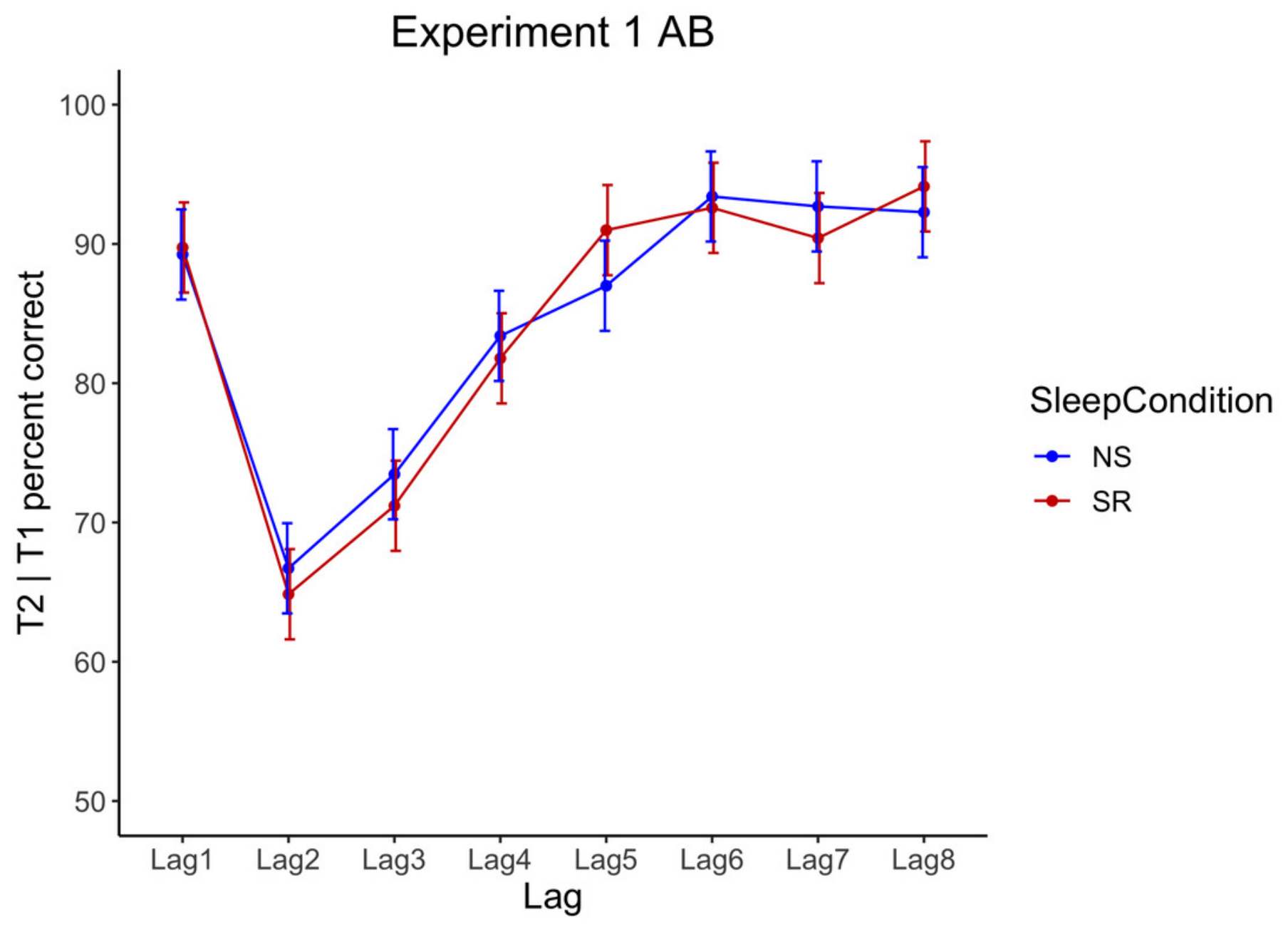




\section{Figure 3}

Experiment 2: Sleep data

Recorded hours of sleep according to the FitBit ${ }^{\circledR}$ and sleep diary (left) and subjective sleepiness (right). Means are shown by black horizontal bars. Individual scores are represented by black circles, slightly jittered for clarity; coloured areas represent 95\% Highest Density Intervals (HDIs), calculated using R's BEST (Bayesian Estimation Supersedes the T-Test) package, and vertical bars represent the 10th and 90th quantiles. 


\section{Sleep restriction results}

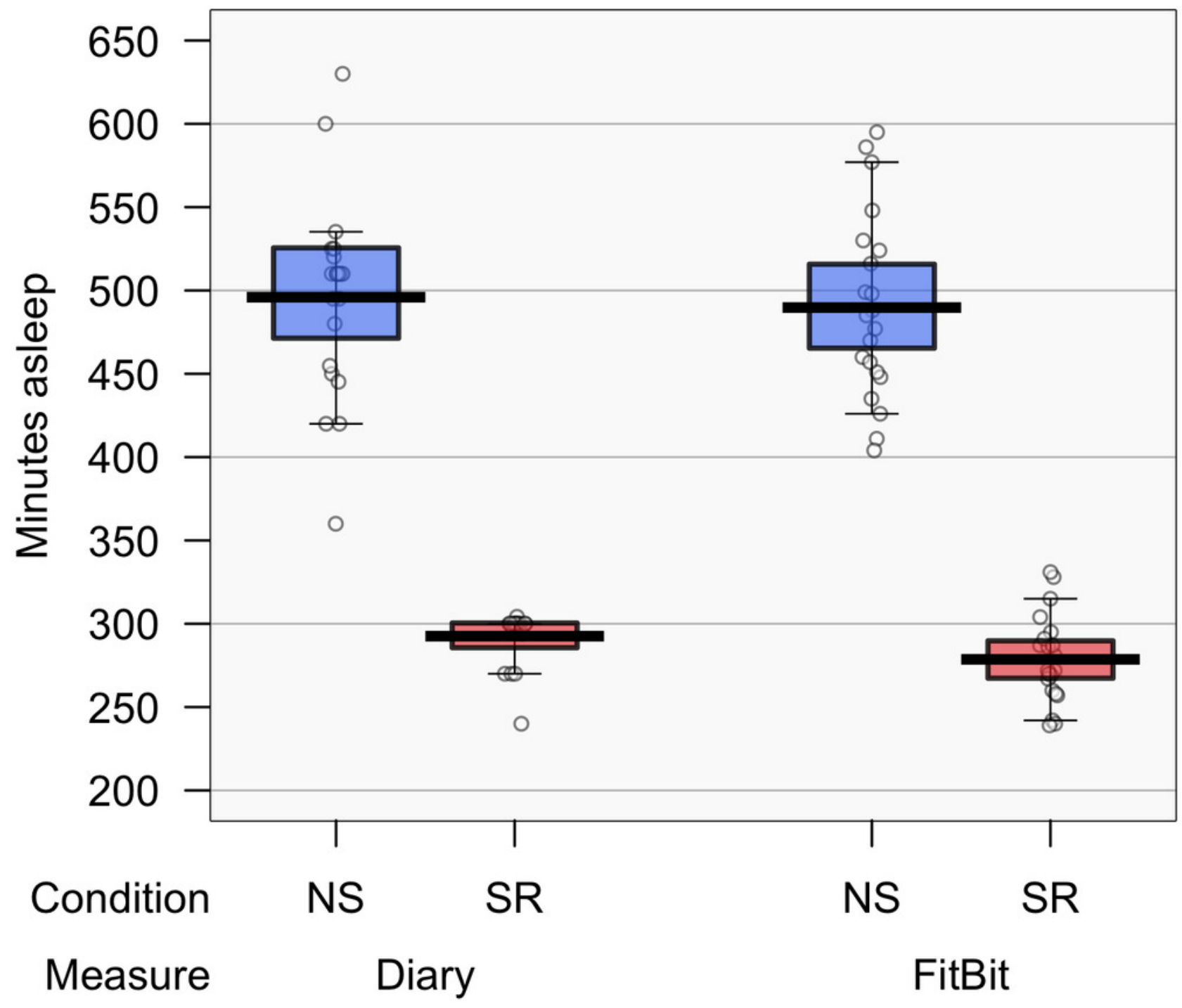


Figure 4

Experiment 2: KSS data and PVT performance

Karolinska Sleepiness Scale ratings (a) and PVT performance (b) during normal sleep (NS) and sleep restriction (SR). Means are shown by black horizontal bars. Individual scores are represented by black circles, slightly jittered for clarity; coloured areas represent $95 \%$ Highest Density Intervals (HDIs), calculated using R's BEST (Bayesian Estimation Supersedes the T-Test) package, and vertical bars represent the 10th and 90th quantiles.

a)

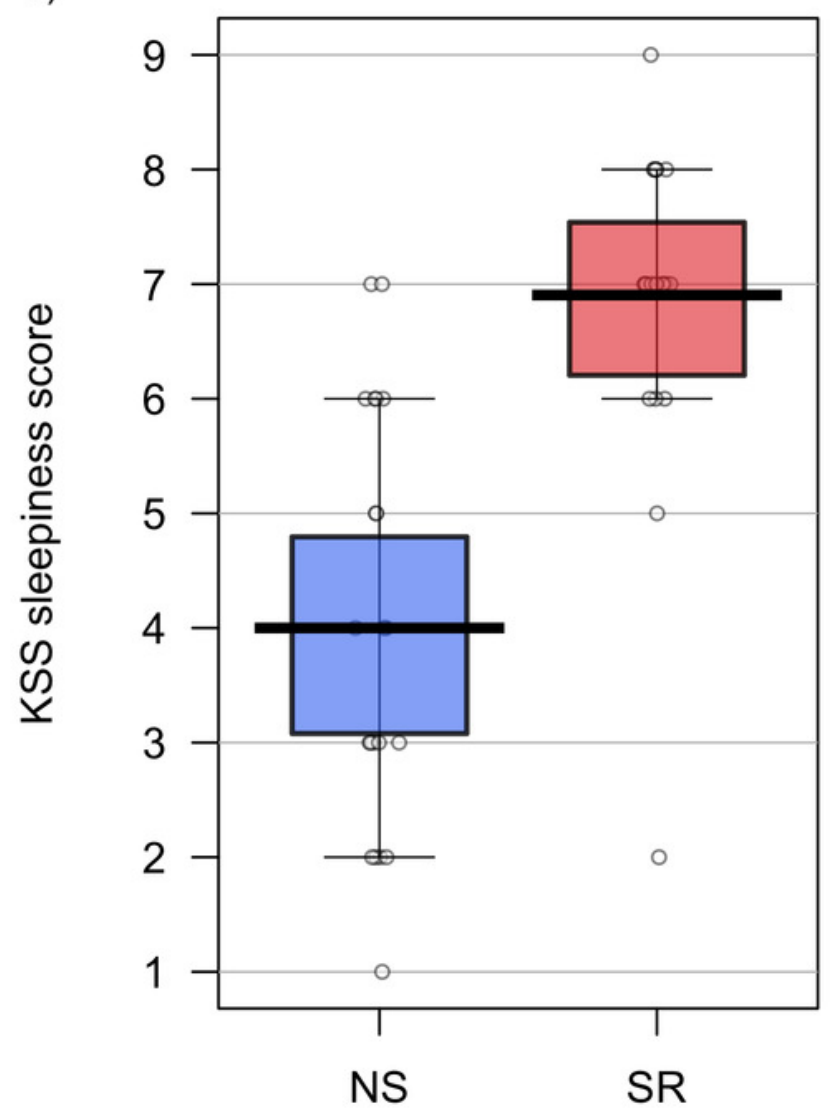

Sleep condition b)

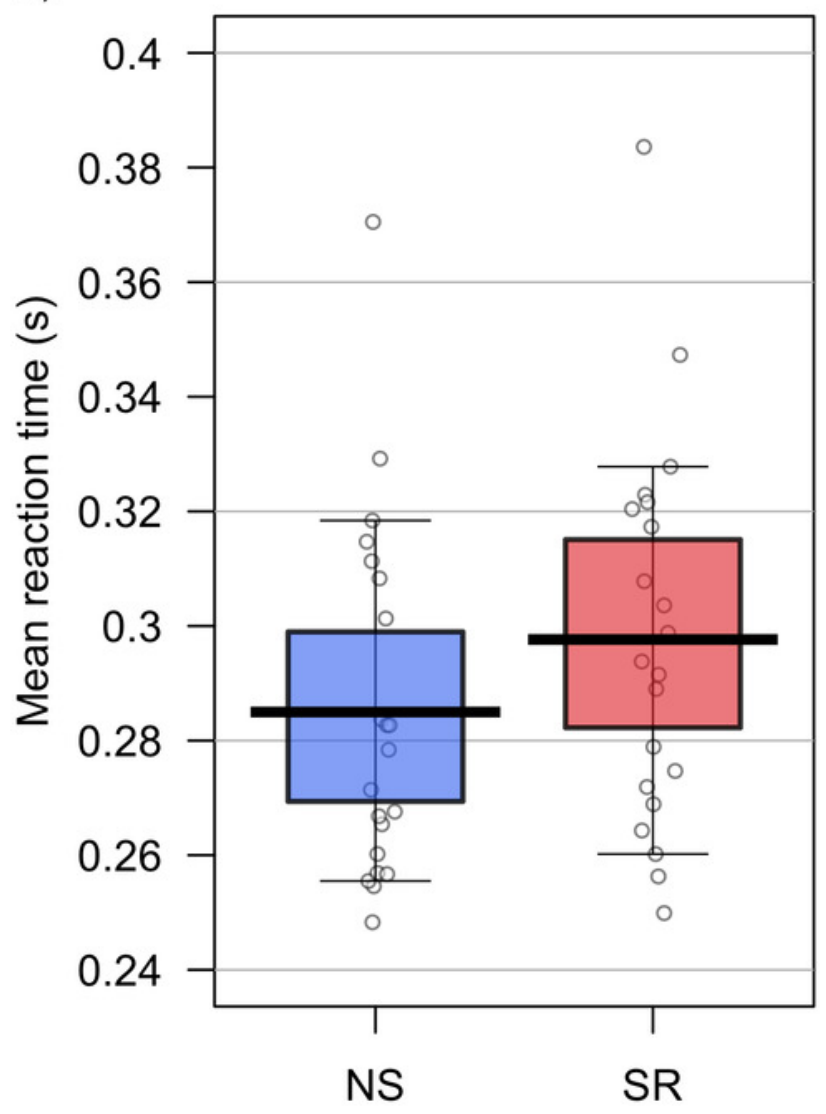

Sleep condition 
Figure 5

Experiment 2 Attentional Blink performance

Behavioural data for the $\mathrm{AB}$ task - the proportion of $\mathrm{T} 2 \mid \mathrm{T} 1$ correctly identified by lag. Error bars show +/- 1 SE around the mean.

Experiment $2 \mathrm{AB}$

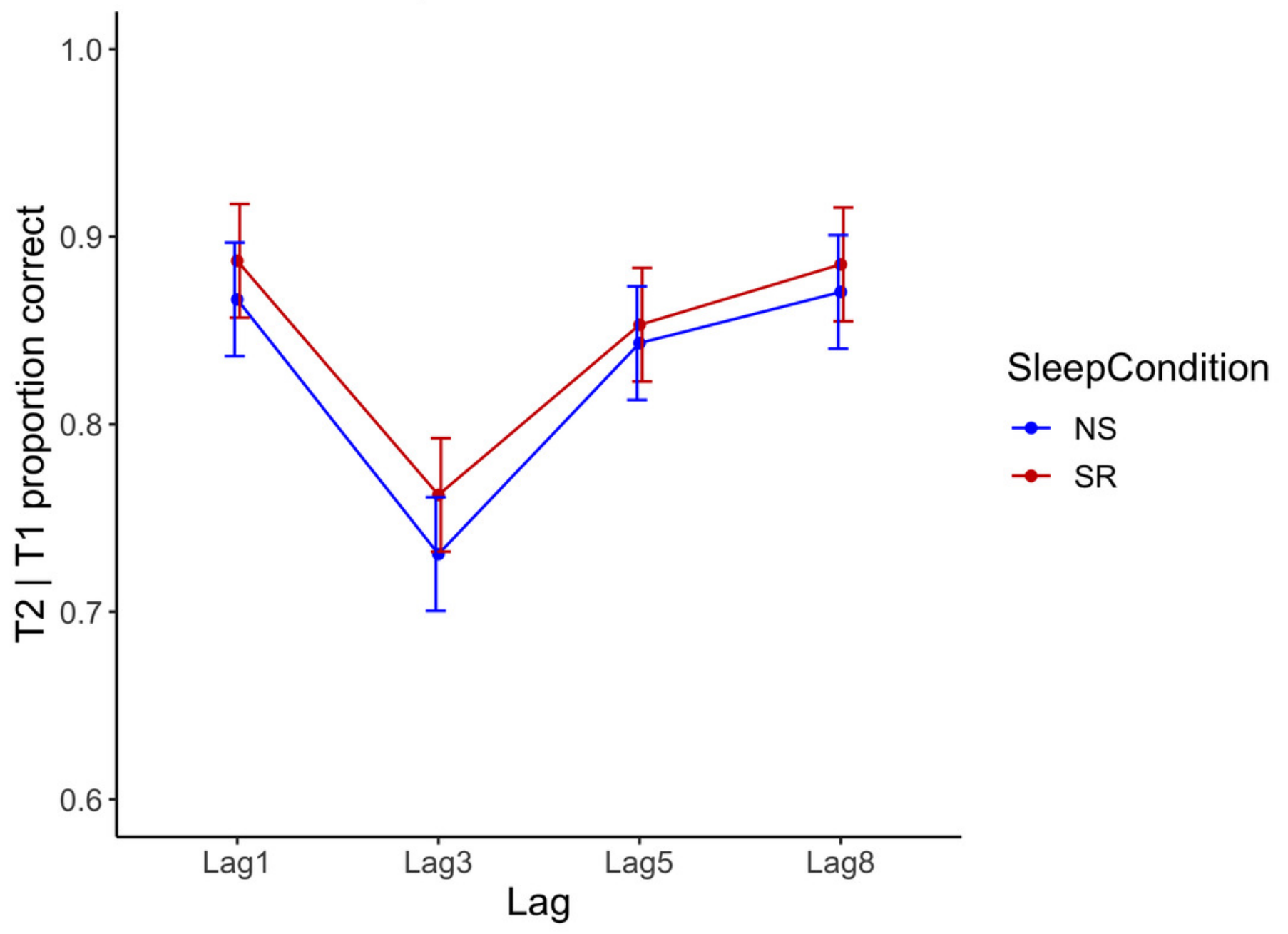


Figure 6

Relative alpha and delta frequencies for normal sleep and sleep restriction conditions

Relative resting state frequency for alpha and delta bands in normal sleep (NS) and sleep restriction (SR) conditions in the right central ROI. Means are shown by black horizontal bars. Individual scores are represented by black circles, slightly jittered for clarity; coloured areas represent 95\% Highest Density Intervals (HDIs), calculated using R's BEST (Bayesian Estimation Supersedes the T-Test) package, and vertical bars represent the 10th and 90th quantiles.

a)

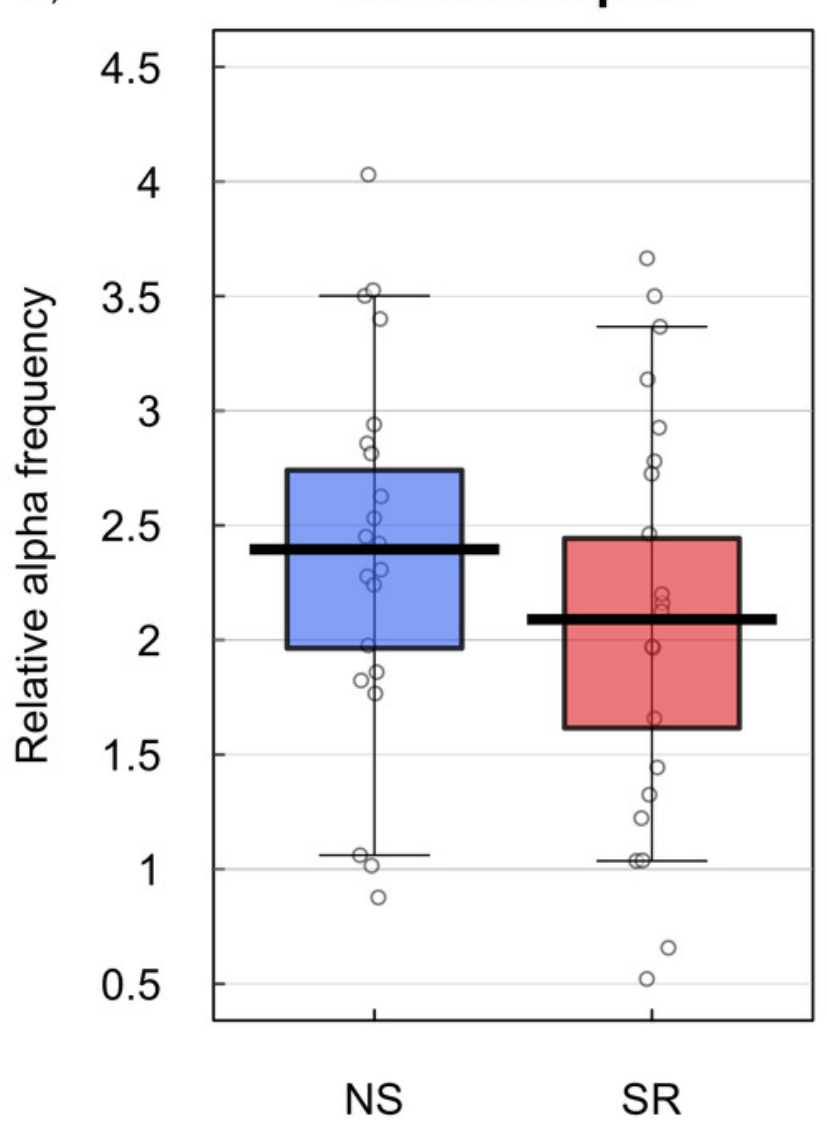

Sleep condition b)

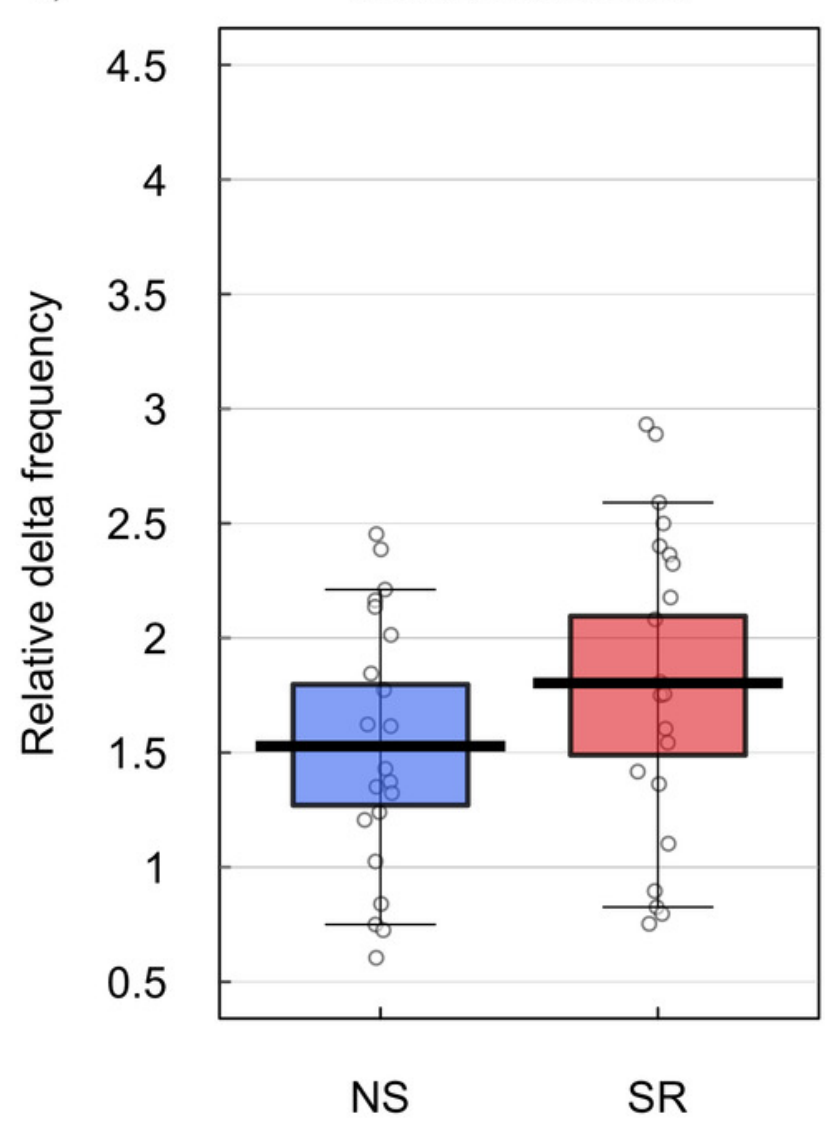

Sleep condition 
Figure 7

EEG spectral power for a representative subject

Variation in spectral power for a single individual during normal sleep (a) and sleep

restriction (b) conditions. Figures constructed in EEGLab (Delorme \& Makeig, 2004). 

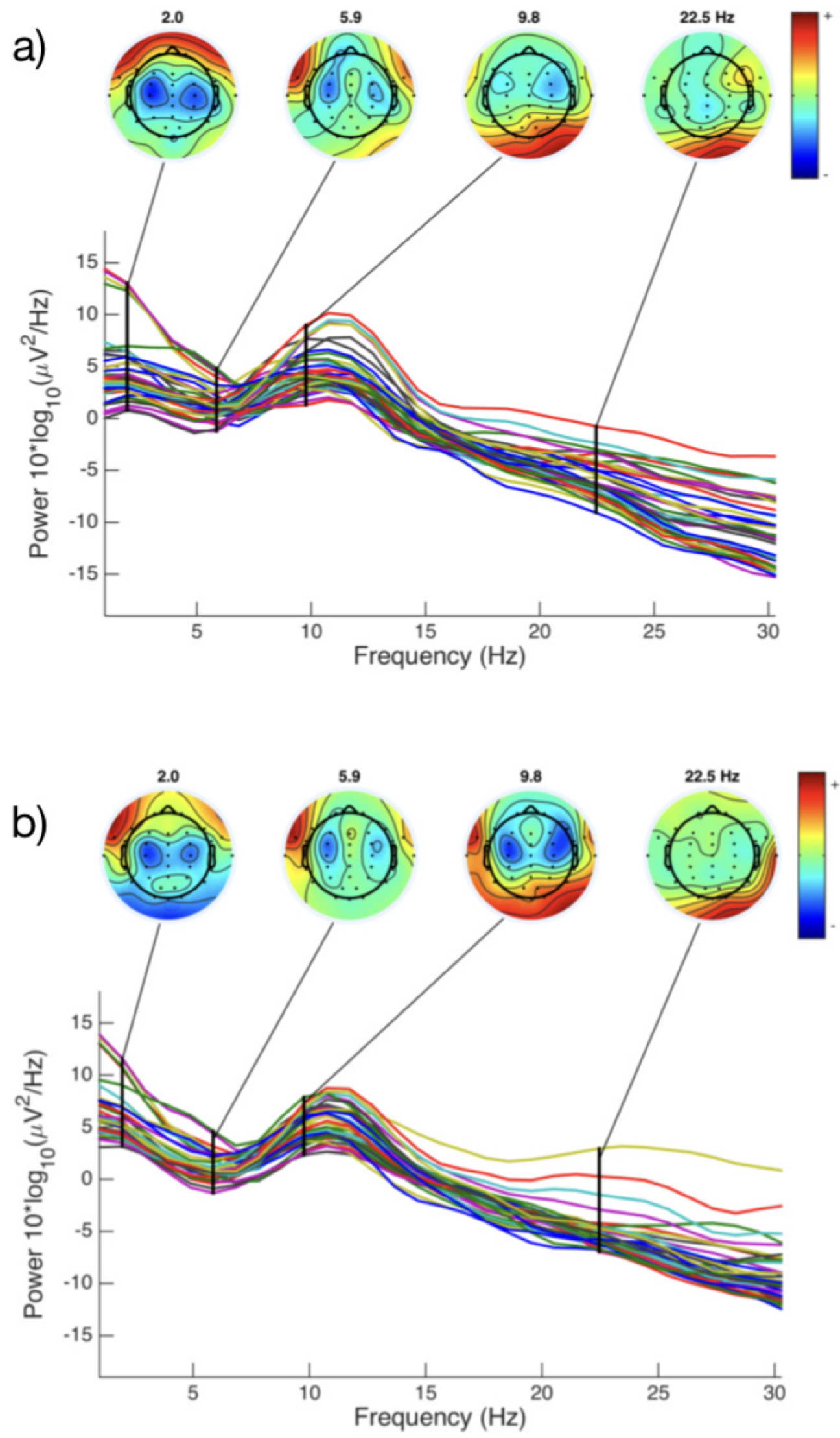
Figure 8

Correlations between behavioural measures and EEG data

Correlations between changes in PVT performance, changes in sleepiness, and EEG changes in alpha (top) and delta (bottom) between normal sleep and sleep restriction conditions.
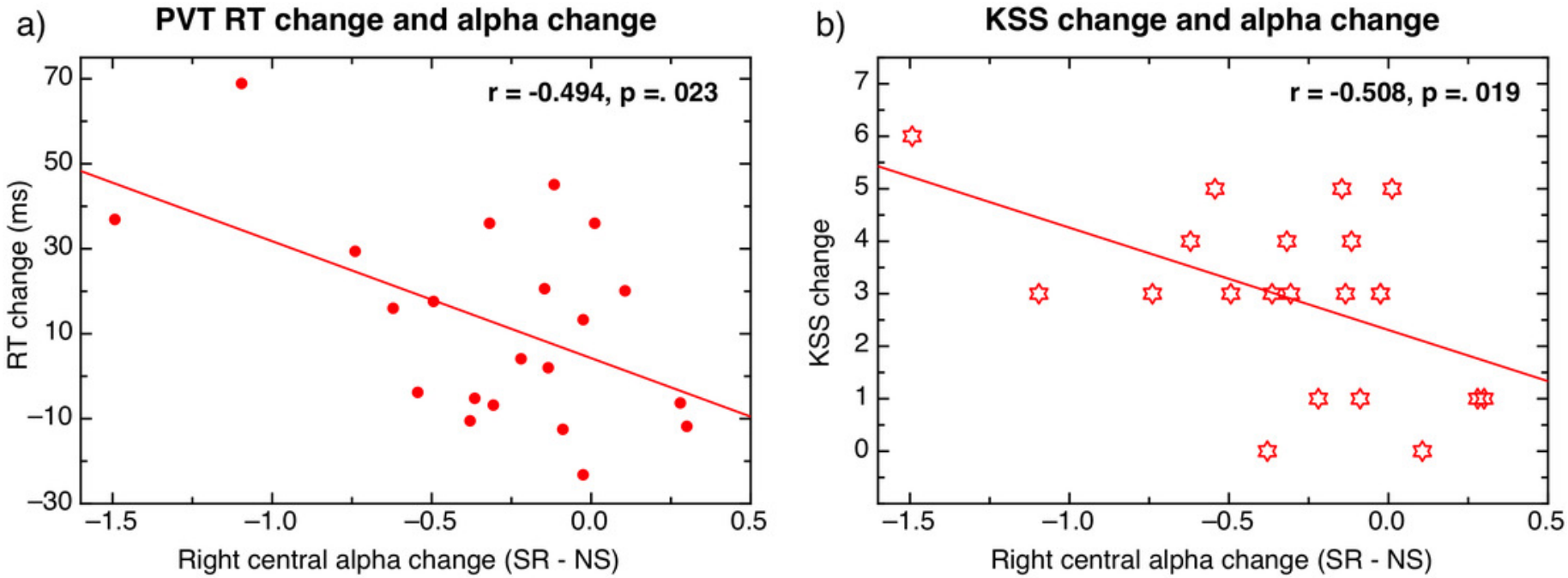

c) PVT RT change and delta change

d)
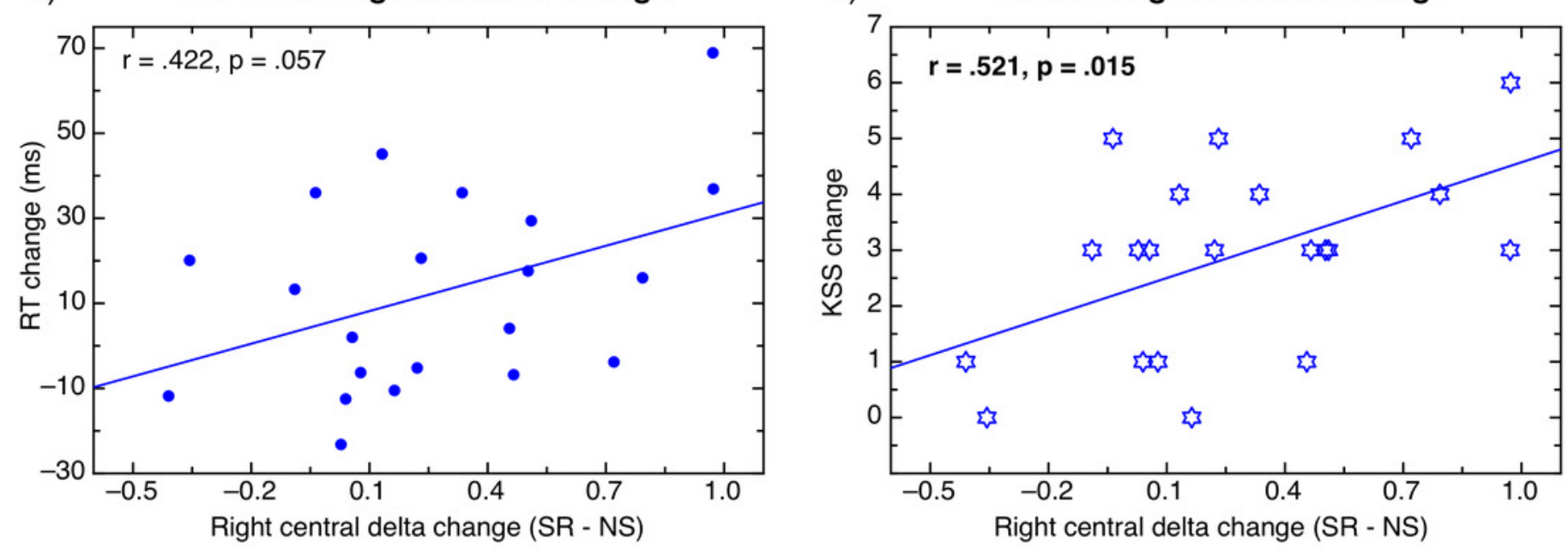


\section{Table $\mathbf{1}$ (on next page)}

\section{Experiment 1: Sleep data}

Duration of sleep and subjective sleepiness by testing session.

$*$ denotes significance at $\alpha=.05$ 
1 Table 1. Duration of sleep and subjective sleepiness by testing session.

\begin{tabular}{lccc}
\hline & Normal sleep & Sleep restriction & $t$-test (2-tailed) \\
\hline Previous night's sleep (minutes) & $467(50)$ & $297(18)$ & \\
Previous night's sleep (hours) & 7.8 & 5.0 & \\
KSS on arrival & $3.0(0.3)$ & $5.1(0.4)$ & $t_{(23)}=6.03, p<.001^{*}$ \\
KSS prior to leaving & $3.9(0.4)$ & $5.9(0.5)$ & $t_{(23)}=4.36, p<.001^{*}$ \\
\hline * & & &
\end{tabular}

3 


\section{Table 2 (on next page)}

\section{Experiment 1: PVT data}

PVT results - means and standard error of the mean.

$*$ denotes significance at $\alpha=.05$ 
1 Table 2. PVT results - means and standard error of the mean.

\begin{tabular}{llll}
\hline & Normal sleep & $\begin{array}{l}\text { Sleep } \\
\text { restriction }\end{array}$ & t-test (2-tailed) \\
\hline Reciprocal RT & $4.14(0.11)$ & $3.71(0.15)$ & $t_{(23)}=3.37, p=.003^{*}$ \\
RRT SD & $0.84(0.16)$ & $0.72(0.07)$ & $t_{(23)}=0.68, p=.287$ \\
Reciprocal slowest 10\% & $2.99(0.12)$ & $2.49(0.16)$ & $t_{(23)}=3.90, p=.001^{*}$ \\
Mean number of lapses (sqrt) & $0.26(0.11)$ & $1.24(0.32)$ & $t_{(23)}=-2.80, p=.010^{*}$ \\
Mean number of false starts (sqrt) & $1.24(0.20)$ & $0.80(0.22)$ & $t_{(23)}=2.07, p=.050$ \\
\hline
\end{tabular}

*denotes significance at $\alpha .05$ 
Table 3 (on next page)

Experiment 2: ROls

Regions of interest and corresponding electrode groupings. 
1 Table 3. Regions of interest and corresponding electrode groupings.

\begin{tabular}{ll}
\hline Region of interest & Electrodes \\
\hline Left frontal & F7, F3, FT7, FC3, FT9 \\
Left central & T3, C3, TP7, CP3 \\
Left occipital & T5, P3, O1, PO1 \\
Right frontal & F4, F8, FC4, FT8, FT10 \\
Right central & C4, T4, CP4, TP8 \\
Right occipital & P4, T6, O2, PO2 \\
\hline
\end{tabular}

2 


\section{Table 4 (on next page)}

Experiment 2: $A B$ lag comparisons

Wilcoxon signed-rank test results for lags in NS and SR conditions. 
1 Table 4. Wilcoxon signed-rank test results for lags in NS and SR conditions.

\begin{tabular}{cccccc}
\hline Lag & $\begin{array}{c}\text { Sleep } \\
\text { Condition }\end{array}$ & Median & $Z$ & Sig. & $R$ \\
\hline 1 & NS & .93 & -.29 & .775 & -0.06 \\
& SR & .93 & & & \\
3 & NS & .78 & -.66 & .509 & -0.14 \\
& SR & .81 & -.36 & .722 & -0.09 \\
5 & NS & .89 & & & \\
& SR & .91 & -.10 & .922 & -0.02 \\
\hline
\end{tabular}

2 


\section{Table 5 (on next page)}

Experiment 2: Comparisons of absolute and relative alpha

Results of paired-samples t-tests for log of absolute and relative spectral alpha.

${ }^{*} p<.008$ indicates a significant difference. Confidence intervals were created using the Bonferroni corrected alpha level (.008) 
1 Table 5. Results of paired-samples t-tests for log of absolute and relative spectral alpha.

\begin{tabular}{|c|c|c|c|c|c|c|c|c|c|c|}
\hline \multirow[b]{3}{*}{ Region } & \multicolumn{4}{|c|}{ Groups } & \multirow[b]{3}{*}{$N$} & \multirow[b]{3}{*}{$d f$} & \multirow[b]{3}{*}{$t$} & \multirow[b]{3}{*}{ Sig. } & \multirow[b]{3}{*}{$d$} & \multirow[b]{3}{*}{$99 \%$ CI } \\
\hline & \multicolumn{2}{|c|}{$\begin{array}{l}\text { Normal Sleep } \\
\text { (NS) }\end{array}$} & \multicolumn{2}{|c|}{$\begin{array}{c}\text { Sleep } \\
\text { Restriction } \\
\text { (SR) }\end{array}$} & & & & & & \\
\hline & $M$ & $S D$ & $M$ & $S D$ & & & & & & \\
\hline \multicolumn{11}{|l|}{ Absolute power } \\
\hline Log left frontal & 1.14 & .93 & .92 & .22 & 21 & 20 & 2.62 & .016 & 0.57 & $-0.06,1.19$ \\
\hline Log left central & 1.03 & .19 & .74 & .20 & 21 & 20 & 2.97 & $.008 *$ & 0.65 & $0.01,1.28$ \\
\hline Log left occipital & 2.12 & .24 & 1.88 & .26 & 21 & 20 & 1.91 & .070 & 0.42 & $-0.19,1.02$ \\
\hline Log right frontal & 1.07 & .19 & .86 & .20 & 21 & 20 & 2.23 & .037 & 0.49 & $-0.13,1.10$ \\
\hline Log right central & 1.20 & .21 & .86 & .22 & 21 & 20 & 3.12 & $.005 *$ & 0.68 & $0.03,1.32$ \\
\hline Log right occipital & 2.39 & .25 & 2.10 & .27 & 21 & 20 & 2.66 & .015 & 0.58 & $-0.05,1.20$ \\
\hline \multicolumn{11}{|l|}{ Relative power } \\
\hline Left frontal & 1.85 & .19 & 1.69 & .19 & 21 & 20 & 1.54 & .139 & 0.34 & $-0.26,0.93$ \\
\hline Left central & 2.21 & .19 & 1.96 & .16 & 21 & 20 & 2.48 & .022 & 0.54 & $-0.08,1.16$ \\
\hline Left occipital & 3.01 & .19 & 2.90 & .22 & 21 & 20 & 0.84 & .441 & 0.18 & $-0.40,0.76$ \\
\hline Right frontal & 1.74 & .17 & 1.60 & .18 & 21 & 20 & 1.54 & .140 & 0.34 & $-0.06,0.73$ \\
\hline Right central & 2.40 & .18 & 2.09 & .21 & 21 & 20 & 3.25 & $.004 *$ & 0.71 & $0.06,1.35$ \\
\hline Right occipital & 3.18 & .19 & 3.00 & .22 & 21 & 20 & 1.83 & .083 & 0.40 & $-0.21,1.00$ \\
\hline
\end{tabular}

$* p<.008$ indicates a significant difference. Confidence intervals were created using the Bonferroni corrected alpha level (.008) 


\section{Table 6(on next page)}

\section{Experiment 2: Comparisons of relative spectral delta}

Results of paired-samples t-tests for relative spectral delta.

$* p<.008$ indicates a significant difference. Confidence intervals were created using the Bonferroni corrected alpha level (.008) 
1 Table 6. Results of paired-samples t-tests for relative spectral delta.

\begin{tabular}{cccccccccccc}
\hline \multicolumn{1}{c}{ Groups } \\
& $\begin{array}{c}\text { Normal Sleep } \\
\text { (NS) }\end{array}$ & \multicolumn{1}{c}{$\begin{array}{c}\text { Sleep Restriction } \\
\text { (SR) }\end{array}$} \\
Region & $M$ & $S D$ & $M$ & $S D$ & $N$ & $d f$ & $t$ & Sig. & $d$ & $99 \%$ CI \\
\hline Left frontal & 2.19 & .16 & 1.32 & .17 & 21 & 20 & -1.13 & .273 & -0.25 & $0.00,0.82$ \\
Left central & 1.96 & .16 & 1.87 & .13 & 21 & 20 & -1.54 & .140 & -0.34 & $0.00,0.92$ \\
Left occipital & 1.20 & .14 & 1.25 & .15 & 21 & 20 & -0.53 & .602 & -0.12 & $0.00,0.68$ \\
Right frontal & 2.27 & .17 & 2.44 & .16 & 21 & 20 & -1.46 & .161 & -0.32 & $0.00,0.90$ \\
Right central & 1.53 & .12 & 1.80 & .15 & 21 & 20 & -3.28 & $.004^{*}$ & -0.72 & $0.01,1.36$ \\
Right occipital & 1.09 & .13 & 1.20 & .14 & 21 & 20 & -1.47 & .158 & -0.32 & $0.00,0.90$ \\
\hline
\end{tabular}

$* p<.008$ indicates a significant difference. Confidence intervals were created using the Bonferroni corrected alpha level (.008)

2 